\title{
hnRNP A1 controls HIV-1 mRNA splicing through cooperative binding to intron and exon splicing silencers in the context of a conserved secondary structure
}

\author{
CHRISTIAN KROUN DAMGAARD, ${ }^{1}$ THOMAS ØSTERGAARD TANGE, ${ }^{1,2}$ \\ and JØRGEN KJEMS ${ }^{1}$ \\ ${ }^{1}$ Department of Molecular and Structural Biology, University of Aarhus, DK-8000 Aarhus C, Denmark
}

\begin{abstract}
The removal of the second intron in the HIV-1 rev/tat pre-mRNAs, which involves the joining of splice site SD4 to SA7, is inhibited by hnRNP A1 by a mechanism that requires the intronic splicing silencer (ISS) and the exon splicing silencer (ESS3). In this study, we have determined the RNA secondary structure and the hnRNP A1 binding sites within the $3^{\prime}$ splice site region by phylogenetic comparison and chemical/enzymatic probing. A biochemical characterization of the RNA/protein complexes demonstrates that hnRNP A1 binds specifically to primarily three sites, the ISS, a novel UAG motif in the exon splicing enhancer (ESE) and the ESS3 element, which are all situated in experimentally supported stem loop structures. A mutational analysis of the ISS region revealed that the core hnRNP A1 binding site directly overlaps with a major branchpoint used in splicing to SA7, thereby providing a direct explanation for the inhibition of U2 snRNP association with the pre-mRNA by hnRNP A1. Binding of hnRNP A1 to the ISS core site is inhibited by RNA structure but strongly stimulated by the exonic silencer, ESS3. Moreover, the ISS also stimulate binding of hnRNP A1 to the exonic splicing regulators ESS3 and the ESE. Our results suggest a model where a network is formed between hnRNP A1 molecules situated at discrete sites in the intron and exon and that these interactions preclude the recognition of essential splicing signals including the branch point.
\end{abstract}

Keywords: exon splicing silencer; hnRNP A1; intron splicing silencer; RNA footprinting; RNA splicing; RNA structure

\section{INTRODUCTION}

The precise excision of introns from precursormessenger RNAs (pre-mRNAs) by splicing is an essential process in the expression of most metazoan genes. Retroviruses are dependent on alternative splicing of a single primary transcript to form multiple mRNA species. In human immunodeficiency virus type-1 (HIV-1), inefficient splicing of the 9.2-kb primary transcript produces more than 30 different mRNAs (Purcell \& Martin, 1993) that can be divided into three main classes. The multiply spliced 2-kb class that encodes Rev, Tat, and Nef proteins, the singly spliced 4-kb class that encodes the Env, Vpu, Vpr, and Vif proteins, and the unspliced transcript, which both encodes the structural proteins Gag/Gag-Pol and serves as the RNA

Reprint requests to: Jørgen Kjems, Department of Molecular and Structural Biology, University of Aarhus, C.F. Møllers Allé, Building 130, DK-8000 Aarhus C, Denmark; e-mail: Kjems@biobase.dk.

2 Present address: Brandeis University, Waltham, MA 02454-9110 USA. genome of progeny virions. An important feature for this regulation is the presence of non-consensus $3^{\prime}$ splice sites, where the pressence of purines in the polypyrimidine tracts and nonconsensus branchpoint sequences contribute to inefficient spliceosome assembly (Staffa \& Cochrane, 1994; Amendt et al., 1995; DyhrMikkelsen \& Kjems, 1995; O'Reilly et al., 1995; Si et al., 1997, 1998). In addition, splicing is also regulated by cellular splicing factors that function via splicing enhancers and silencers in the HIV-1 transcript. The most thoroughly investigated splicing process in HIV-1 is the splicing of the two tat introns. The first tat intron is negatively regulated by at least two exon splicing silencer (ESS) elements in the second tat exon, named ESS2 and ESS2p (Amendt et al., 1994, 1995; Staffa \& Cochrane, 1995; Jacquenet et al., 2001a; Fig. 1). Splicing of the second tat intron is stimulated by two exonic splicing enhancers, ESE2 and ESE3, situated in second and third tat exon, respectively (Amendt et al., 1995; Staffa \& Cochrane, 1995; Kammler et al., 2001) and inhibited by at least two silencer elements, the ESS3 and the intron splicing silencer (ISS) positioned in the 


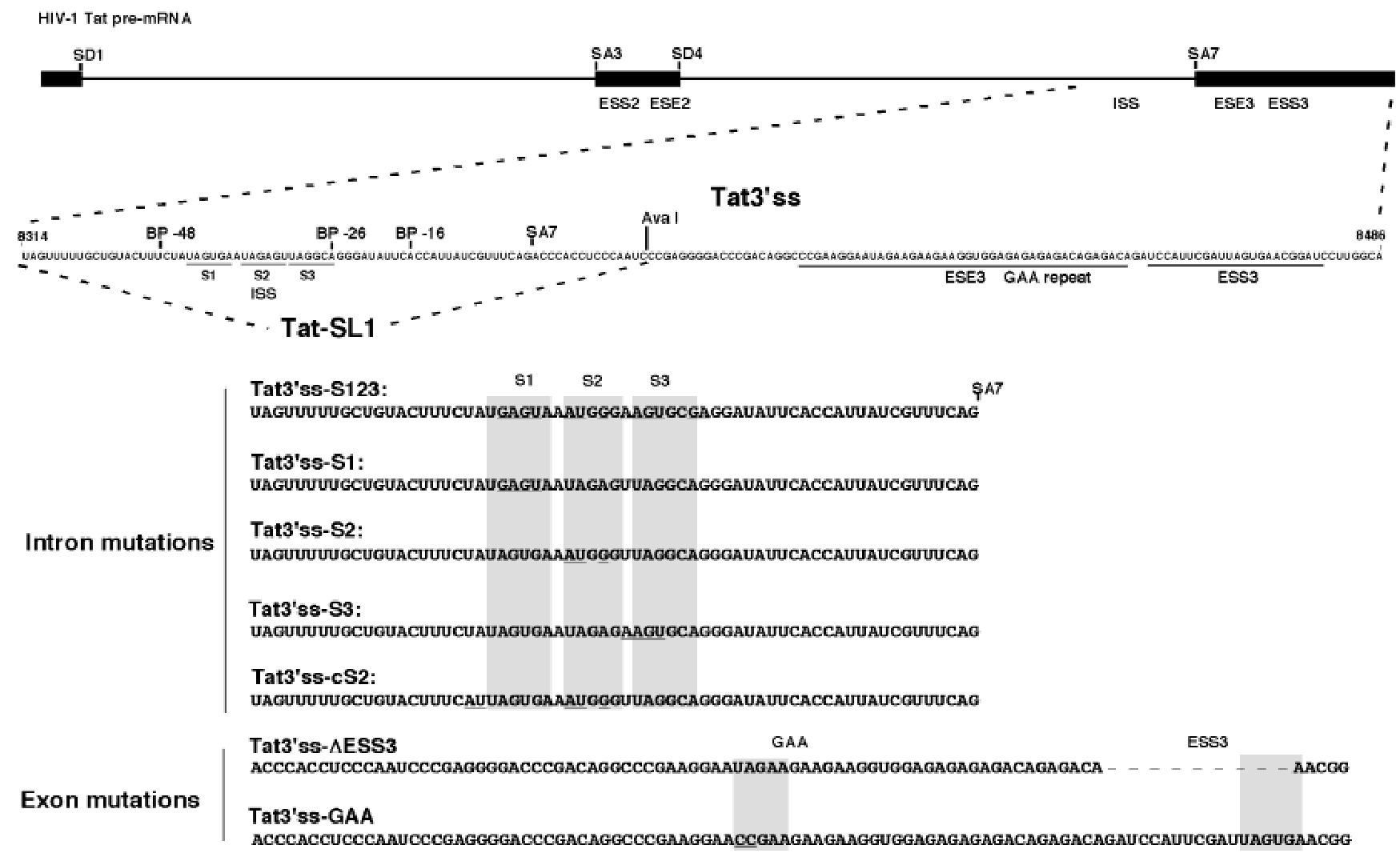

FIGURE 1. RNA constructs used in this study. The structure of the tat pre-mRNA is shown at the top with exons and introns indicated by thick and thin lines, respectively. The splice donor (SD), splice acceptor (SA), and the splicing enhancer and silencer sequences implicated in the regulation of tat pre-mRNA splicing are indicated. GAA indicates the position of the GAA sequence repeat. The constructs used in this study are shown as expansions below. Sequences that resembles the hnRNP A1 consensus binding motif are shaded, and the mutated nucleotides are underlined. BP denotes the experimentally determined branchpoints and their nucleotide position $-48,-26$, and -16 relative to SA7 (T. Ø. Tange \& J. Kjems, submitted).

third tat exon and second tat intron, respectively (Amendt et al., 1995; Staffa \& Cochrane, 1995; Tange et al., 2001; Fig. 1). The trans-acting splicing factors that recognize the positive and negative splicing signals have in some instances been characterized. The SR protein, SF2/ASF, has been implicated as a positive splicing factor acting via degenerate enhancer elements in ESE2 and ESE3 (Mayeda et al., 1999; Kammler et al., 2001; Tange \& Kjems, 2001). The negative factors that have been characterized all belong to the group of heterogeneous nuclear ribonucleoproteins (hnRNPs). The ESS2, ESS3, and ISS function at an early step in spliceosome assembly by recruiting members of hnRNP A/B protein family (Amendt et al., 1995; Si et al., 1998; Caputi et al., 1999; Del Gatto-Konczak et al., 1999; Tange et al., 2001), whereas the inhibition of splicing by the ESS2p appears to be mediated by hnRNP H (Jacquenet et al., 2001a). The mechanism by which hnRNP A1 inhibits splicing of the second tat intron via the ISS and ESS3 has recently been investigated (Tange et al., 2001; Zhu et al., 2001). Zhu et al. presented evidence for hnRNP A1 binding to the ESS3, leading to a nucleation of upstream exon sequences, which interferes with the binding of splicing factors and that this effect was counteracted by SF2/ASF (Zhu et al., 2001). We found that binding of hnRNP A1 to both the ISS and ESS3 contributes to the silencing of tat intron splicing by blocking the association of the U2 snRNP with the branchpoints (Tange et al., 2001).

The hnRNP A/B proteins have in numerous cases been implicated in the regulation of alternative splice site selection, the regulation of telomere biogenesis, and mRNA transport/trafficking (Mayeda \& Krainer, 1992; Eperon et al., 1993, 2000; Mayeda et al., 1994, 1998; Yang et al., 1994; Visa et al., 1996; Chabot et al., 1997; Izaurralde et al., 1997; Carson et al., 1998; Hoek et al., 1998; LaBranche et al., 1998; Blanchette \& Chabot, 1999; Munro et al., 1999), suggesting that these proteins possess multifunctional roles in the cell. The binding properties of hnRNP A1 to different nucleic acid substrates have been thoroughly investigated (Cobianchi et al., 1988; Swanson \& Dreyfuss, 1988; Ishikawa et al., 1993; Mayeda et al., 1994, 1998; Shamoo et al., 1995; Abdul-Manan et al., 1996; Abdul-Manan \& Williams, 1996; LaBranche et al., 1998; Blanchette \& Chabot, 1999; Dallaire et al., 2000; Eperon et al., 2000; Shan et al., 2000; Fiset \& Chabot, 2001) and a consensus sequence (UAGGGA/U) for high affinity bind- 
ing has been identified by SELEX (Burd \& Dreyfuss, 1994). From these studies, it is evident that hnRNP A1 interacts with nucleic acids over a broad range of affinities consistent with the notion that hnRNP A/B proteins possess both a nonspecific and a sequencespecific mode of recognition (Mayeda et al., 1998; Shan et al., 2000). Recently, the crystal structure of the UP1 domain of hnRNP A1 in a complex with an oligodeoxynucleotide (TTAGGGTTAGGG) has been solved and the TAGG motif was inferred as the minimal recognition sequence (Ding et al., 1999). However, little is known about the influence of local RNA structure on the binding of hnRNP A1 in a pre-mRNA context.

In this study, we analyze the hnRNP A1 binding sites and the secondary structure of an RNA, spanning the entire splice acceptor 7 (SA7) region of the tat gene. We find that hnRNP A1 interacts primarily with three UAG-containing motifs within the ISS, the ESE3, and in the ESS3 elements that are located in experimentally verified stem loop regions. A more detailed characterization of the ISS element revealed a core site that overlaps with a functional branchpoint in splicing, providing a direct explanation for the observation that binding of hnRNP A1 sterically blocks the U2 snRNP association (Tange et al., 2001). Moreover, our results show that binding of hnRNP A1 to specific sites in the RNA occurs cooperatively and depends on the structural context of these regions.

\section{RESULTS}

\section{The HIV-1 ISS and ESS3 are situated in conserved hairpin structures}

The recognition of RNA by cellular factors is presumably influenced by RNA structure. To address the question of whether RNA structure may play a role in regulating the splicing of the second HIV-1 tat intron (SD4 to SA7), we first analyzed an RNA fragment spanning positions 8314-8486 of HIV-1 strain HXB3 (Tat3'ss; Fig. 1) using phylogenetic comparison and enzymatic/ chemical probing techniques. This RNA encompasses all known regulatory elements reported to influence the $3^{\prime}$ splice site recognition, including the ISS, ESE3, and ESS3. Using the free energy minimization computer program, MFOLD (version 3.1), this region is predicted to fold into a stable secondary structure that, except for minor modifications, resembles the experimentally supported structure shown in Fig. 2C. The predicted secondary structure was insensitive to addition of $300 \mathrm{nt}$ of authentic HIV-1 sequence at the termini, supporting the existence of such a structure in HIV-1 genomic RNA.

The suggested RNA structure is composed of three major stem loops (SL1-3) that contain the ISS, ESE3, and ESS3, respectively (Fig. 2C). SL1 and SL3 can be formed among the HIV-1 clades belonging to the major
(M) group (Fig. 3), whereas SL2 was not readily formed in all clades (data not shown). Sequences of isolates belonging to the outliner- $(O)$ type viruses did not support the folding of any of the proposed stem loops. However, the presence of sequence elements containing UAG motifs at conserved positions in the majority of isolates belonging to group $O$ suggests that these viruses might also be subject to a similar regulation by members of the hnRNP A/B family.

The proposed structure was generally consistent with our enzymatic and chemical probing experiments, and the minor discrepancies could generally be accounted for by sliding of bulges and internal loops (Fig. 2A, B; the results are summarized in Fig. $2 \mathrm{C}$ ). The apical loops of SL1, SL2, SL3, and the loop, containing a GAArepeat in SL2 (8420-8429), were highly reactive towards single-strand-specific RNases and chemicals, whereas the double-strand-specific enzyme, RNase V1, generally cleaved within double-stranded segments. Some regions were inert to all probing agents. In particular, the $3^{\prime}$ side of SL1 (8341-8352) that contains two of the three hnRNP A1 consensus binding sites, S2 and S3, within the ISS (Fig. 1; Tange et al., 2001) was much more inaccessible to RNase V1 than the complementary region (8322-8335; Fig. 2C), suggesting that it may be buried in tertiary interactions. In contrast, the SL3 that encompasses the ESS3 element was exposed to double-strand-specific cleavages on both sides of the stem region and hypersensitive to RNases $\mathrm{T} 1$ and T2 in the apical loop, clearly supporting the validity of the SL3 structure (Fig. 2A, C).

\section{hnRNP A1 binds to discrete sites in the ISS, ESE3, and the ESS3 elements}

We have recently shown that hnRNP A1 binds directly to an intron RNA fragment containing the ISS element and to an exon RNA fragment containing the ESS3 (Tange et al., 2001). A sequence analysis of the fragments revealed that the ISS fragment contains three putative UAG-containing hnRNP A1 binding motifs and the exon fragment 2 sites (Fig. 2C). To further delineate the binding sites of hnRNP A1 within these regions, we performed RNA footprinting experiments on both 5'and 3 '-end-labeled Tat3'ss RNA in the presence of increasing concentrations of recombinant hnRNP A1 protein (Fig. 4A, B; the results are summarized in Fig. 4C). The most pronounced protections were seen in the apical loops of SL1 and SL3 using RNase T1 and T2 (Fig. 4A, lanes 3-5 and 9-11; Fig. 4B, lanes 4-9), using RNase T2 in the GAA repeat (Fig. 4A, lanes 9-11), and using RNase $\mathrm{V} 1$ at the $\mathrm{S} 3$ sequence within the ISS and immediately downstream of this site (Fig. 4A; lanes 15-17), suggesting that these elements are the major binding sites for hnRNP A1 proteins (denoted by boxes in Fig. 4C). Weaker protections were observed using RNase V1 and T2 at nt 8325-8335 that com- 
A

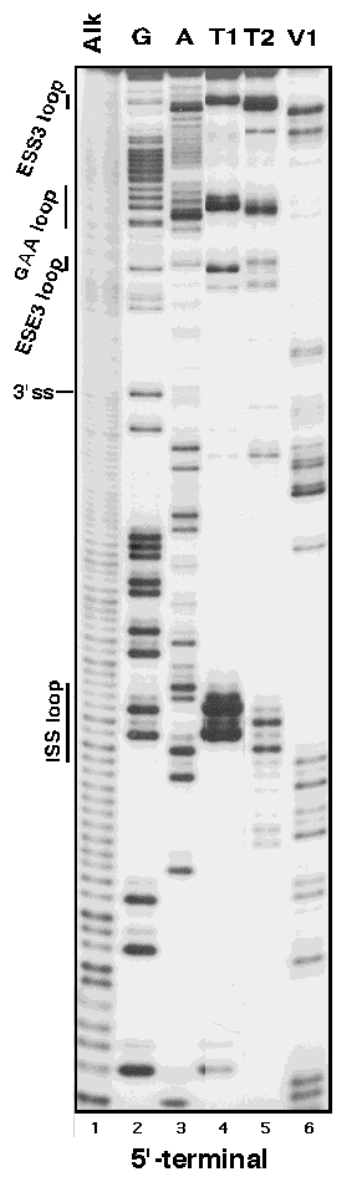

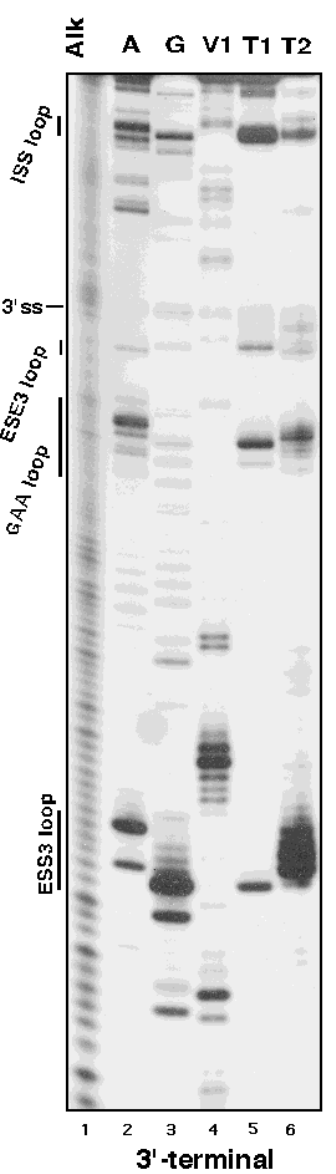

FIGURE 2. Enzymatic and chemical probing of Tat3'ss RNA. A: $5^{\prime}$ or 3' end-labeled Tat3'ss RNA (left and right panels, respectively) was subjected to partial RNase cleavage using the indicated RNases followed by separation of RNA fragments in denaturing polyacrylamide gels. RNases T1 cleaves after single-stranded G-residues, RNase T2 cleaves nonspecifically in single-stranded regions with some preference for $\mathrm{A}$ residues, and RNase V1 cleaves doublestranded regions. An alkaline hydrolysis ladder is included (Alk) together with a partial RNase U2 (A-specific; A) and T1 (G-specific; G) digestion under denaturing conditions. B: Chemical probing of Tat3'ss. Primer extension, using primers complementary to position 8402 8440 (left panel) and 8476-8495 (right panel), was used to detect DMS modifications at $A$ and $C$ residues (lane 1 ) and DEP modifications at $A$ residues (lane 2 ). $K$ (lane 3 ) denotes a control where no chemical was added. A dideoxynucleotide sequencing ladder is included (lane 4-7). A, B: The positions corresponding to the loops of SL1 and SL3, the GAA-rich internal loop of SL2, and the 3' splice site are indicated to the left. C: A secondary structure model of Tat3'ss. The structure is based on computer folding that was modified to conform to the enzymatic and chemical probing data. The three major stem loop structures (SL1-3) are indicated. The data from at least three independent data sets are summarized using the symbols shown in the inserted legend. Nucleotide numbers (HXB2), the RNA termini and $3^{\prime}$ splice site (3'ss) are marked. Outlined fonts denote sequences with homology to the hnRNP A1 binding consensus sequences.
B $\sum_{0}^{\infty} \frac{0}{D^{2}}$

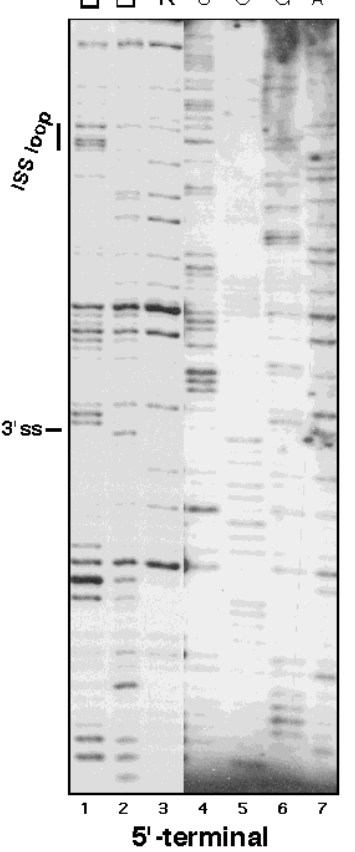

$\sum_{0}^{\infty}$ 岃

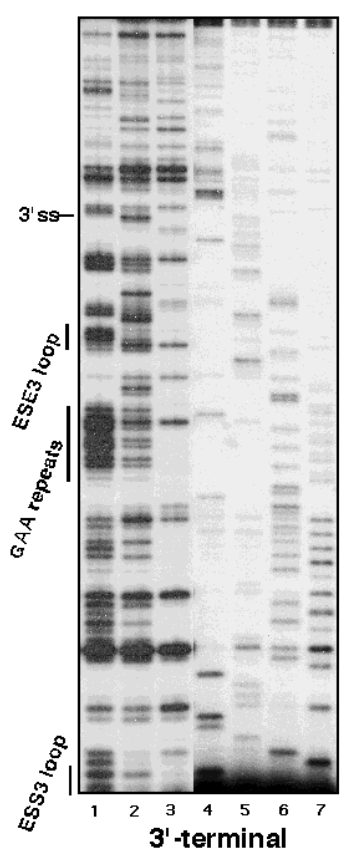

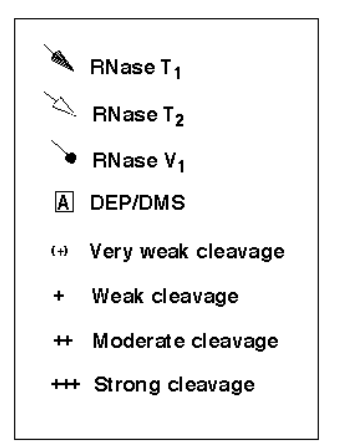

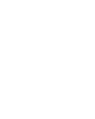

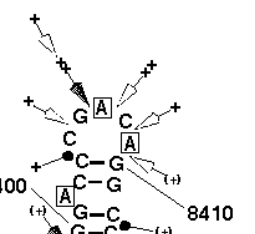
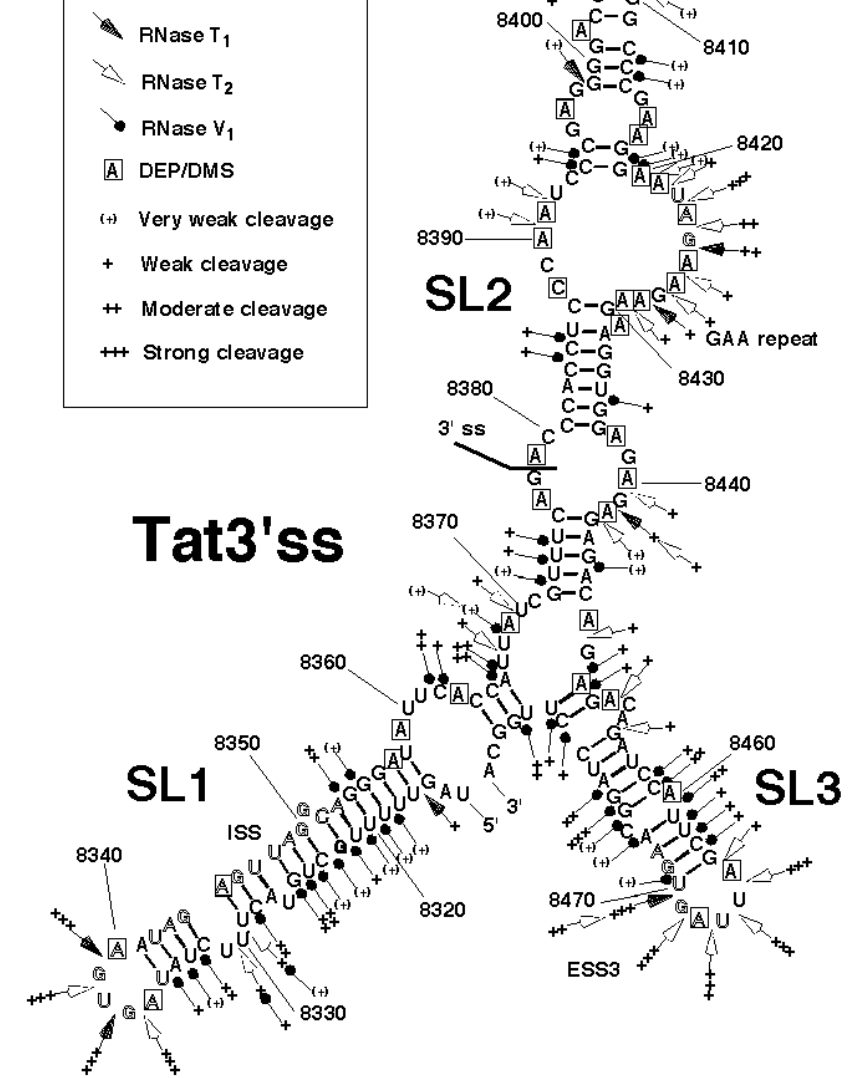

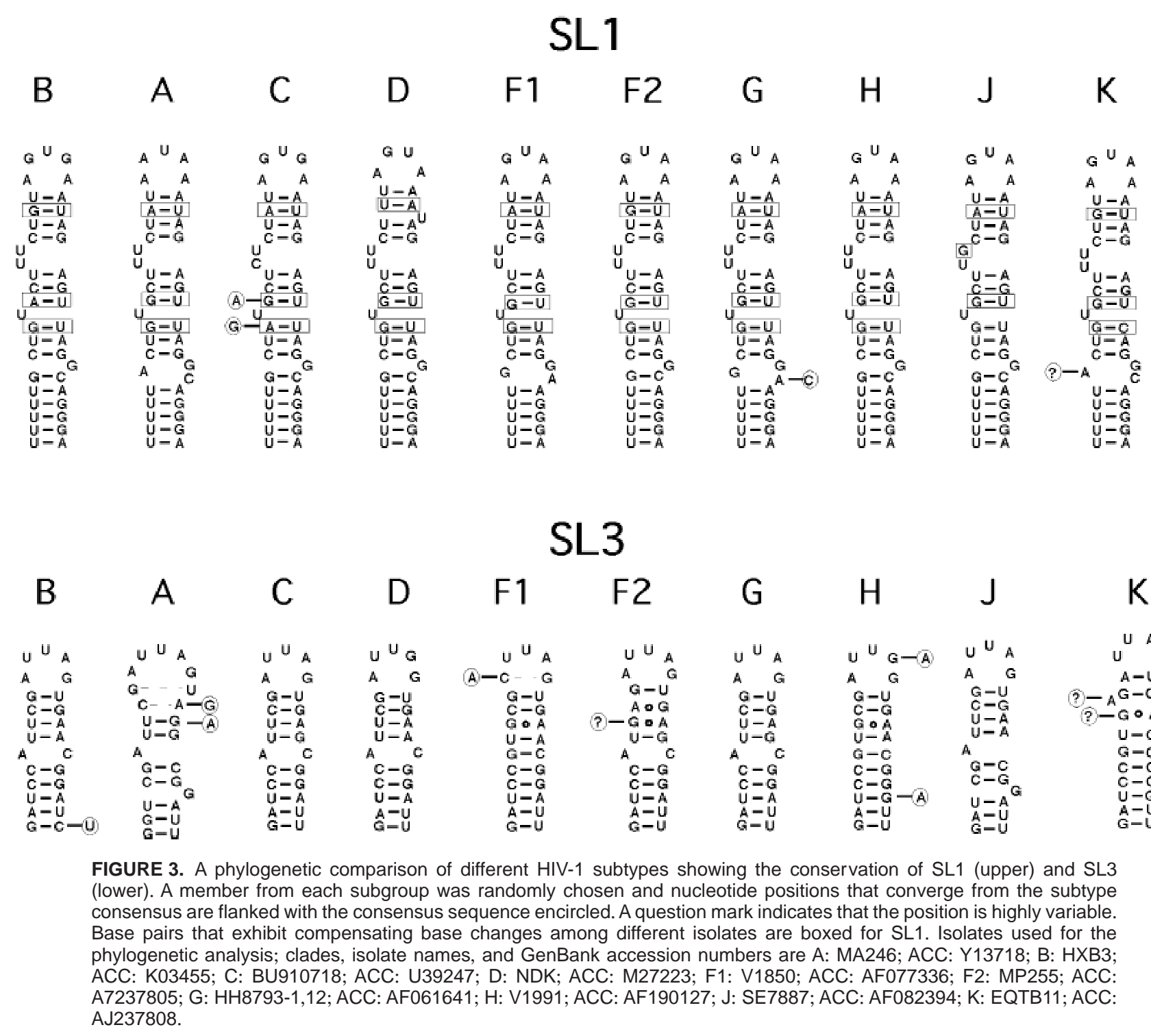

prises the complementary strand to the S2 and S3 elements (Fig. 4A, lanes 9-11 and 15-17), against RNaseV1 at nt 8450-8451 at the three-way junction of the structure (Fig. 4A, lanes 15-17, and Fig. 4B, lanes 11-13), and at the stem of SL3 (Fig. 4B, lanes 11-13). In general, we found a similar hnRNP A1 protection pattern using both $5^{\prime}$ - and $3^{\prime}$-end-labeled Tat3'ss RNA, confirming that it is primary cleavage events that are protected by hnRNPA1 (compare Fig. 4A and $B$ ). We conclude from the footprinting data that hnRNP A1 binds most strongly to discrete sites in the RNA that overlap with the functionally characterized splicing silencers, ISS and ESS3. In addition, hnRNPA1 also interacts strongly with the GAA repeat sequence, which previously has been found to have both enhancing and silencing properties depending on the structural context (Tange \& Kjems, 2001; see discussion below).

\section{Defining a core recognition site for hnRNP A1}

To further investigate the individual roles of the hnRNP A1 binding sites, we performed mobility shift assays using wild type and various point and deletion mutants of the Tat3'ss RNA (Fig. 1). Binding of hnRNP A1 to wild-type Tat3'ss yielded a distinct first-order complex and several slower migrating complexes (Fig. 5, lanes 1-3). Deletion of the ESS3 element (Tat3'ss$\Delta$ ESS3) significantly lowered the formation of all complexes, suggesting that this region is involved in formation of the first complex (Fig. 5, lanes 7-9). Mutating S3 (Tat3'ss-S3) had an intermediate effect on complex formation (Fig. 5, lanes 16-18), whereas mutations in the $\mathrm{S} 1$ or the GAA region (Tat3'ss-S1 and Tat3'ss-GAA, respectively) had only minor effects on 


\section{A}
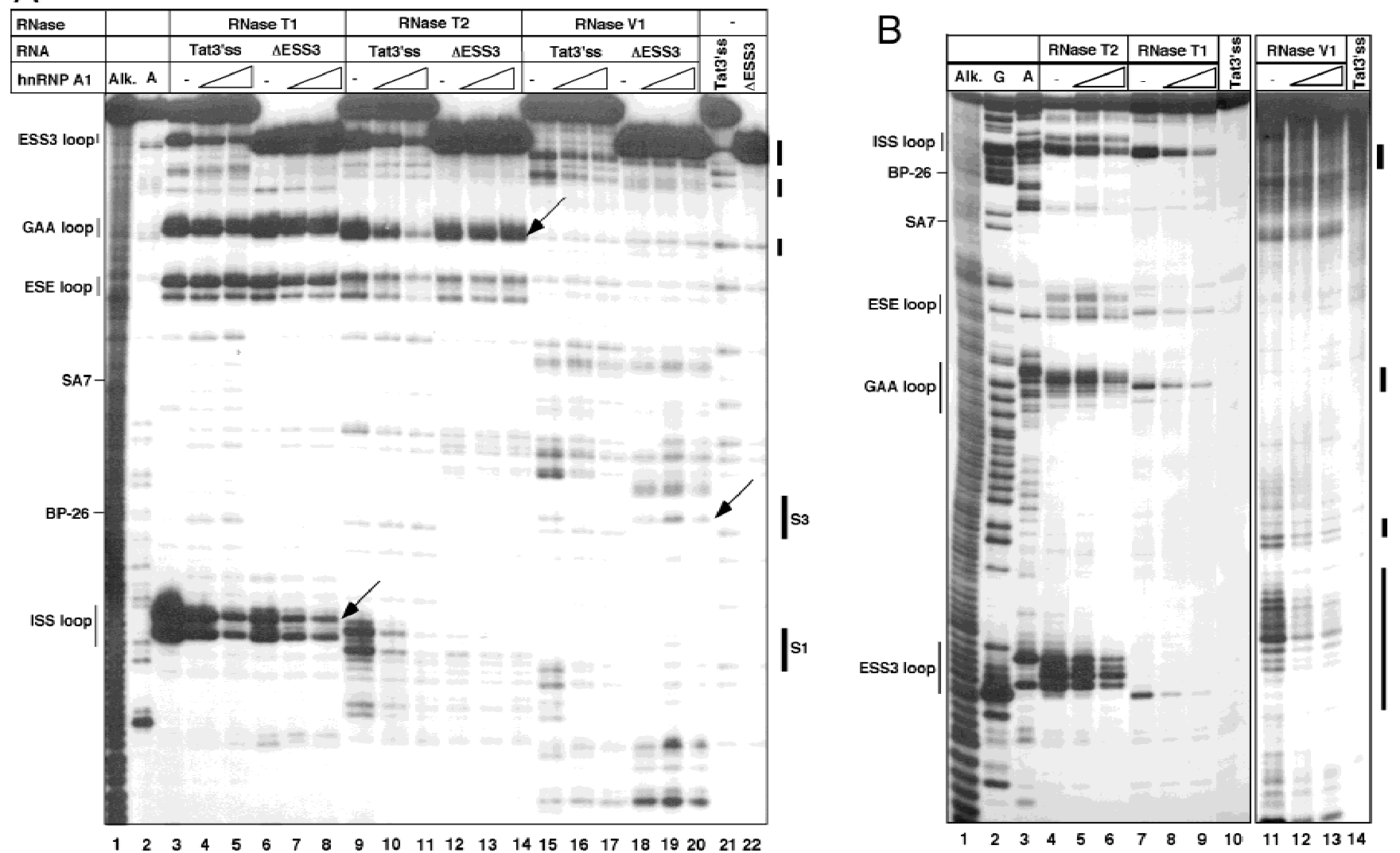

C

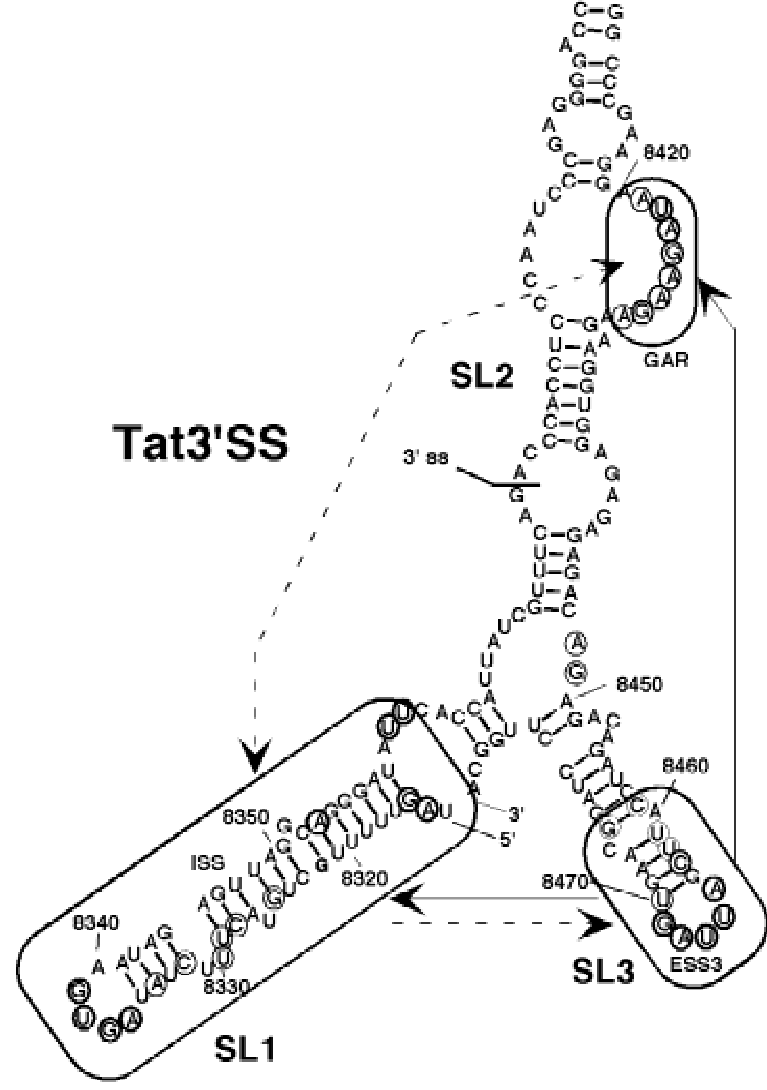

FIGURE 4. Footprinting of hnRNP A 1 on Tat3'ss and Tat 3 'ss- $\Delta$ ESS 3 RNA ( $\triangle$ ESS3) constructs. A: 5'-end labeled Tat3'ss or Tat3'ss$\triangle$ ESS3 RNA (see Fig. 1) was subjected to partial digestion with the indicated RNases in the presence of 0,250 , and $500 \mathrm{ng}$ hnRNP A1 (lanes 3-20). A hydrolysis ladder (lane 1) and A-specific sequence ladder (lane 2) were included as markers. Control lanes for both constructs where no enzyme was added are included (lanes 21-22). The positions of the branchpoint -26 nucleotides upstream of the 3 splice site (BP-26), SA7, and the loop sequences are indicated to the left. The regions that are specifically protected by hnRNP A1 are indicated with bars to the right. B: Same experiment as in A, but using 3'-end labeled Tat3'ss. C: The secondary structure model of Tat3'ss summarizing hnRNP A1-specific protections. Bold and thin circles indicate strong and weak protection, respectively. The regions in the RNA exhibiting major protections from hnRNP A1 are shown by large circles and the cooperativity in binding is indicated by arrows. Thick and stippled arrows indicate that a particular site has a strong or a weak influence by presence of another hnRNP A1 binding site, respectively. 

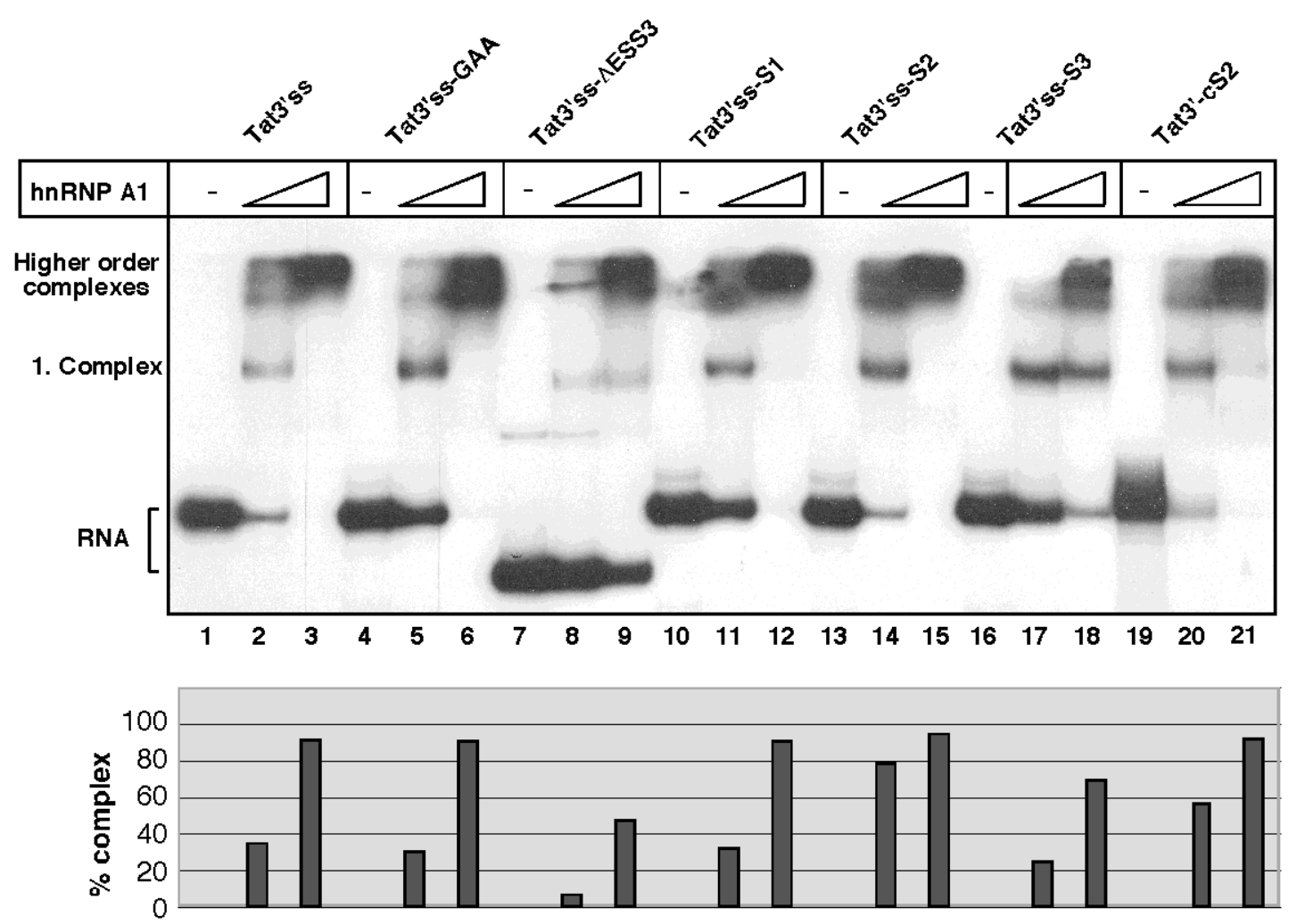

FIGURE 5. Gel shift analysis showing the binding of hnRNP A1 to various RNA fragments. The sequences the RNA fragments are shown in Figure 1. RNA-protein complex formation in presence of increasing concentrations of hnRNP A1 $(0,100,300 \mathrm{ng})$ in a 10- $\mu \mathrm{L}$ volume. The bands, corresponding to free RNA, first-order and higher order complexes that were detected, are marked. The intensities of the bands corresponding to all complexes were quantitated and shown below (percent complex was calculated as total counts in complex/total counts in complex plus free RNA).

the first order complex, but showed some redistribution of the intensities of the bands corresponding to the higher order complexes. Interestingly, the S3 mutation affected the overall formation of higher order complexes most severely, suggesting that the progression from first to higher order complexes involves this element. Mutating the S2 element (Tat3'ss-S2) increased complex formation (Fig. 5A, lanes 13-15), indicating that the $S 2$ sequence is inhibitory to hnRNP A1 binding. These results correlate with the footprinting result and confirm that S3, the GAA-repeat, and the ESS3 constitute the primary binding sites for hnRNP A1.

\section{The accessibility of the hnRNP A1 binding site at $\mathrm{S} 3$ is regulated by secondary structure}

Several lines of evidence suggest that hnRNP A1 bind single-stranded RNA (see Discussion). One explanation for increased binding of hnRNP A1 to the S2 mutant may therefore be that the SL1 stem becomes partially disrupted in the S2 mutant exposing the adjacent hnRNP A1 binding site at S3. To investigate this possibility, we constructed another mutant that poten- tially restored the base-pairing ability of SL1 by mutating the sequence complementary to the S2 site (Fig. 1; Tat3'ss-cS2). Binding of hnRNP A1 to this mutant was significantly lower than to Tat3'ss-S2 and approached that of wild type (Fig. 5, lanes 19-21). To study this phenomenon in further detail, we performed additional binding experiments using an RNA spanning the SL1 alone (Tat-SL1; Fig. 1). The result of the gel shift assay is shown in Figure 6A. In this context, the S3 mutation (Tat-SL1-S3) had the most severe phenotype, almost completely abolishing hnRNP A1 binding (Fig. 6A, lanes 17-20) whereas the S1 mutation (Tat-SL1-S1) only had a minor effect (Fig. 6A, lanes 9-12). The S2 mutation (Tat-SL1-S2) dramatically increased the hnRNP A1 binding (Fig. 6A, lanes 13-16) and restoration of the base pairing in the SL1 stem (Tat-SL1-cS2) reduced the hnRNP A1 binding to wild-type levels. To confirm that the mutations in S2 alone and its complementary strand were accompanied with an opening and closure of the SL1 stem, respectively, we employed enzymatic probing to investigate the secondary structure of wild-type and mutant SL1 RNAs (Fig. 6B; data is summarized in Fig. $6 \mathrm{C}$ ). Mutating the S2 element led to a strong induction of RNase T1 and T2 

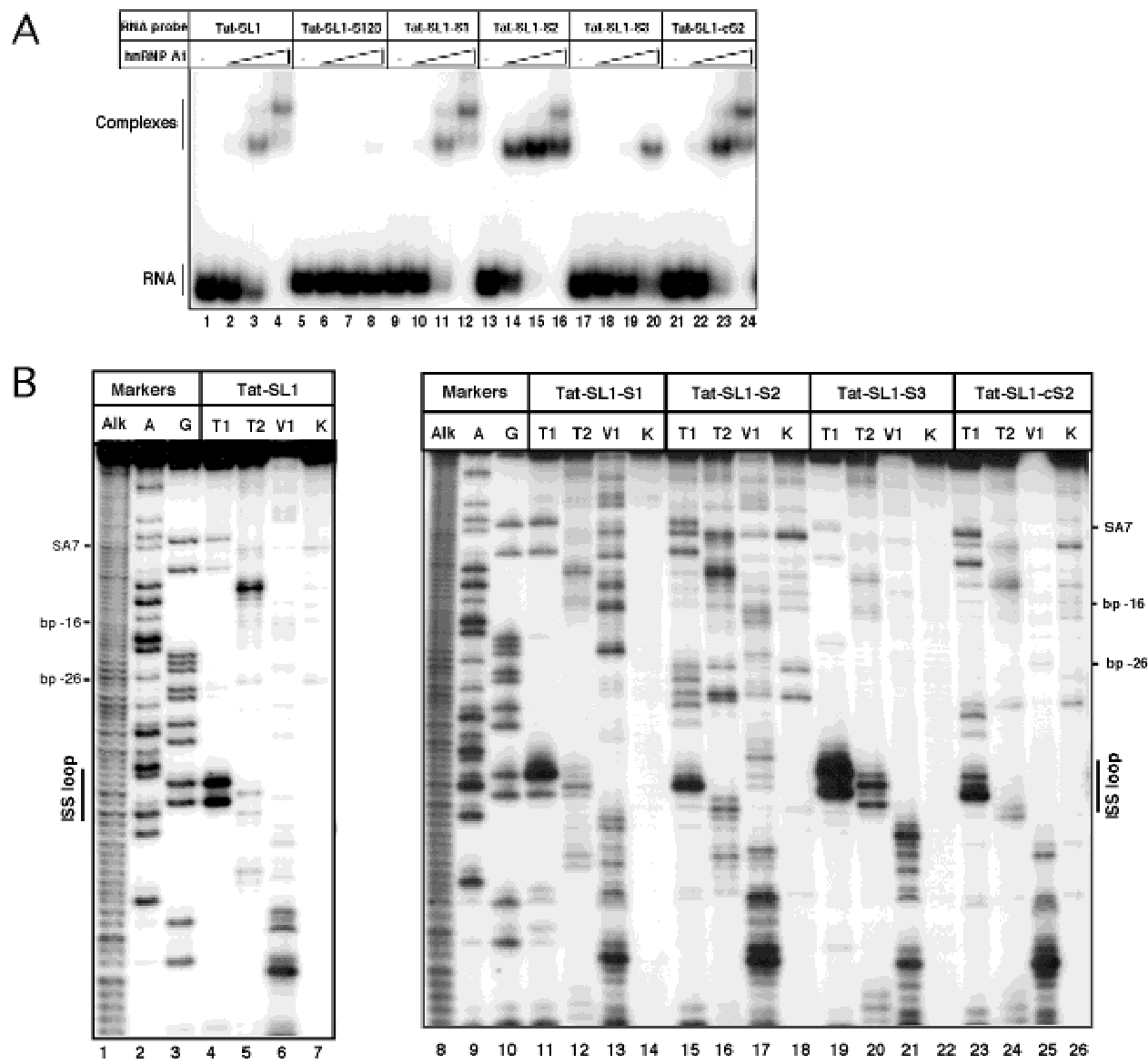

C
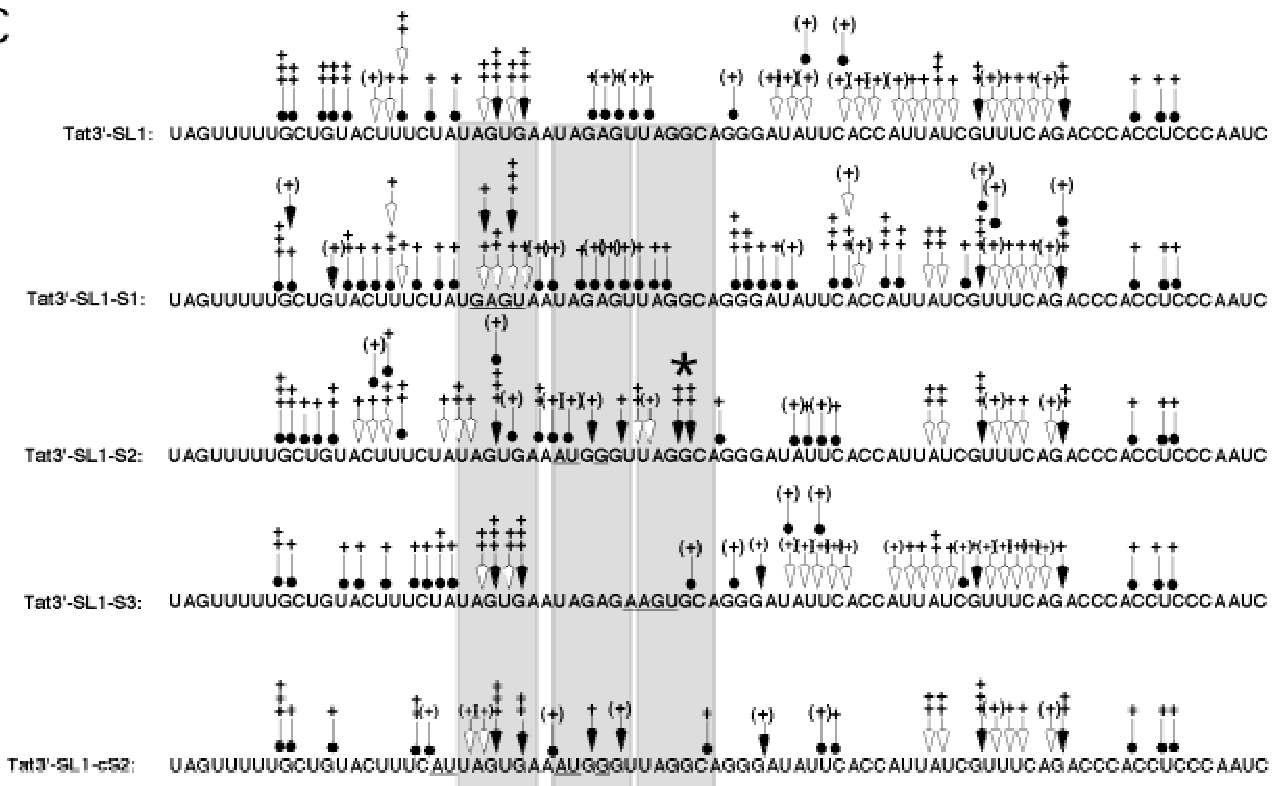

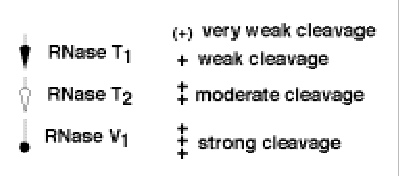

FIGURE 6. hnRNP A1 binding analysis of SL1 alone. A: Gel shift analysis showing the binding of hnRNP A1 to various Tat-SL1 RNA mutants (see Fig. 1 for details). The binding of hnRNP A1 to Tat-SL1 forms two discrete complexes. B: Enzymatic probing of 5' end labeled wild-type or mutated Tat-SL1 RNA as indicated. T1, T2, and V1 indicate the enzymes used (see legend to Fig. 2). Alkaline digestion and A- and G-specific lanes are included as markers (lanes 1-3 and 8-10). C: Summary of the experimental probing data (legend is shown below). See legend to Figure 2 for details. Shaded regions indicate the three hnRNP A1 binding motifs (S1-3) in the ISS. 
cleavages in the $\mathrm{S} 3$ region and a more moderate induction of T1 cleavage at the opposite side of SL1, which is consistent with an opening of the S3 region (Fig. 6B; lanes 19-21; indicated by an asterisk in Fig. 6C). Some degree of structural rearrangement appears to have occurred in the terminal loop in this mutant, which is reflected by the disappearance of the RNase T1 cleavage at G-8339 and the appearance of $\mathrm{R}$ Nase $\mathrm{V} 1$ cleavages in the same region. As predicted, the compensating mutations in the $5^{\prime}$ strand of SL1 reduced the accessibility of the S3 region back to the wild-type level (Fig. 6B, lanes 27-29). The probing of the RNA mutated in the $S 1$ region showed only minor changes compared to the wild-type RNA (Fig. 6B, lanes 15-17), whereas the S3 mutated RNA exhibited some changes in RNaseV1 cleavage activity on the $5^{\prime}$ side of SL1 (Fig. 6B, lanes 23-25). Taken together, these results suggest that binding of hnRNP A1 to the S3 motif is inhibited by local RNA structure, which is disrupted in the S2 mutant.

\section{Cooperative binding of hnRNP A1 to the ESS3, the GAA loop, and ISS}

The ability of hnRNP A1 to form dimers raises the possibility that hnRNP A1 binding to the multiple binding sites for hnRNP A1 in the $3^{\prime}$ splice site region occurs in a cooperative fashion. To investigate a potential cooperativity, we footprinted the binding of hnRNP A1 using Tat 3'ss substrates that contained mutations in the ISS, GAA loop, or ESS3 regions. Interestingly, the protections of the S1, S3, and the GAA loop induced by hnRNP A1 were clearly dependent on the presence of the ESS3 element. In the absence of the ESS3 element, the protections at S3 and the GAA repeat loop was abolished and it was significantly reduced at $\mathrm{S} 1$ (marked by arrows in Fig. 4A, lanes 6-8, 12-14, and 18-20). To perform the reverse experiment, we mutated all three UAG sequences in the ISS (Fig. 1, Tat3'ss-S123) and repeated the footprinting experiment. As expected, this mutant did not bind any hnRNP A1 protein in the ISS, but, more interestingly, the binding of hnRNP A1 to the ESS3 and GAA-loop was significantly reduced (Fig. 7). Finally, we found that mutating the UAG sequence in the GAA loop had an intermediate effect on the hnRNP A1-induced protection at S3 and S1 but no effect on the ESS3 binding (data not shown). We conclude that the binding of hnRNP A1 to the ESS3 plays a major role in recruiting hnRNP A1 to other sites that are distantly positioned in the primary sequence and that the ISS has a more moderate effect on hnRNP A1 binding to the ESS3 and GAA loop regions. Moreover, hnRNP A1 binding to the GAA loop also stimulates hnRNP A1 binding to the ISS. The suggested communication scheme between hnRNP A1 binding sites is summarized by arrows in Fig. $4 \mathrm{C}$.
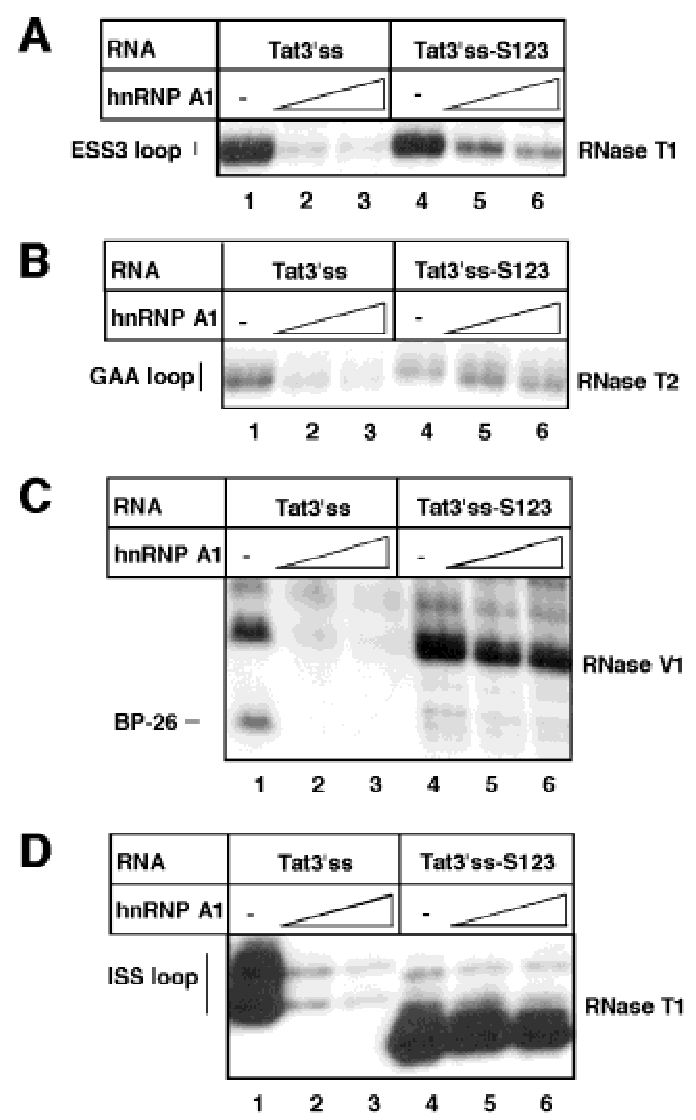

FIGURE 7. Footprinting of hnRNP A 1 on $5^{\prime}$-end-labeled Tat 3 'ss and Tat 3'ss-S123 constructs. All UAG sequences in the ISS have been mutated in Tat3'ss-S123 (Fig. 1). The RNAs were subjected to partial digestion with the indicated RNases in the presence of 0,250 , and $500 \mathrm{ng}$ hnRNP A1. Autoradiograms of selected parts of the same footprinting gel are shown. The protection of the ESS3 from T1 RNase cleavage (A), GAA-loop from RNase T2 cleavage (B), S3 from RNase V1 cleavage (C), and S1 from RNase T1 cleavage (D) are shown.

\section{The S3 sequence in the ISS constitutes an hnRNP A1 responsive core in splicing}

In agreement with our hnRNP A1 binding data, we have previously found that the ISS and the ESS3 elements constitute the major hnRNP A1 responsive silencing elements in an in vitro splicing assay (Tange et al., 2001). To investigate the functional role of the individual S1-S3 sequences elements of the ISS in splicing, we introduced the S1, S2, and S3 mutations, together and individually, into a previously described chimeric splicing substrate PiPtat (Tange et al., 2001), producing the constructs PiPtat-S123, PiPtat-S1, PiPtat-S2, and PiPtat-S3 (see Fig. 1 for details). In these constructs, the $5^{\prime}$ exon and part of the intron originates from PIP7A, and the $3^{\prime}$ part of the intron and the $3^{\prime}$ exon derive from Tat3'ss. We have previously shown that splicing of PIP7A is insensitive to hnRNP A1, whereas the splicing of PiPtat is efficient in hnRNP A1-depleted nuclear extracts but strongly compromised in the presence of recombinant hnRNP A1 protein 
(Tange et al., 2001). Using this construct allowed us to directly assess the inhibitory effect of hnRNP A1 on the usage of the HIV-1 SA7. In agreement with our earlier results (Tange et al., 2001), the splicing of wild-type PiPtat pre-mRNA was clearly inhibited by hnRNP A1 (Fig. 8, lane 2-5), and this effect was almost fully relieved upon scrambling all three hnRNP A1 consensus binding sites in the intron (PIPtat-S123; Fig. 8, lanes, 7-10). Introducing the S1 mutation in PIPtat (PIPtatS1) had only a very little effect (Fig. 8, compare lanes 21-24 with 25-28), whereas the S2 mutation (PIPtat-S2) resulted in a slight increase in splicing, along with a stronger response to hnRNP A1 than wild type (Fig. 8, compare lanes 2-5 with 12-15). Mutating the S3 element (PIPtat-S3) almost eliminated the responsiveness to hnRNP A1, resembling the effect of scrambling all S1-S3 sequences (Fig. 8, compare lanes 7-10 and 17-20). We conclude that S3 constitutes the functional hnRNP A1 responsive core of the ISS.

\section{DISCUSSION}

Inefficient splicing of the HIV-1 genome is required to preserve a pool of unspliced and singly spliced transcripts, to be transported across the nuclear membrane via the Rev/RRE dependent pathway. Besides having suboptimal splice sites, exonic and intronic sequences in the tat pre-mRNA function as binding sites for cellular factors of the hnRNP A/B and hnRNP $\mathrm{H}$ classes, which leads to further inhibition of splicing (Amendt et al., 1994, 1995; Staffa \& Cochrane, 1994, 1995; Si et al., 1997, 1998; Caputi et al., 1999; Del Gatto-Konczak et al., 1999; Jacquenet et al., 2001a; Tange et al., 2001; Zhu et al., 2001). Here, we have
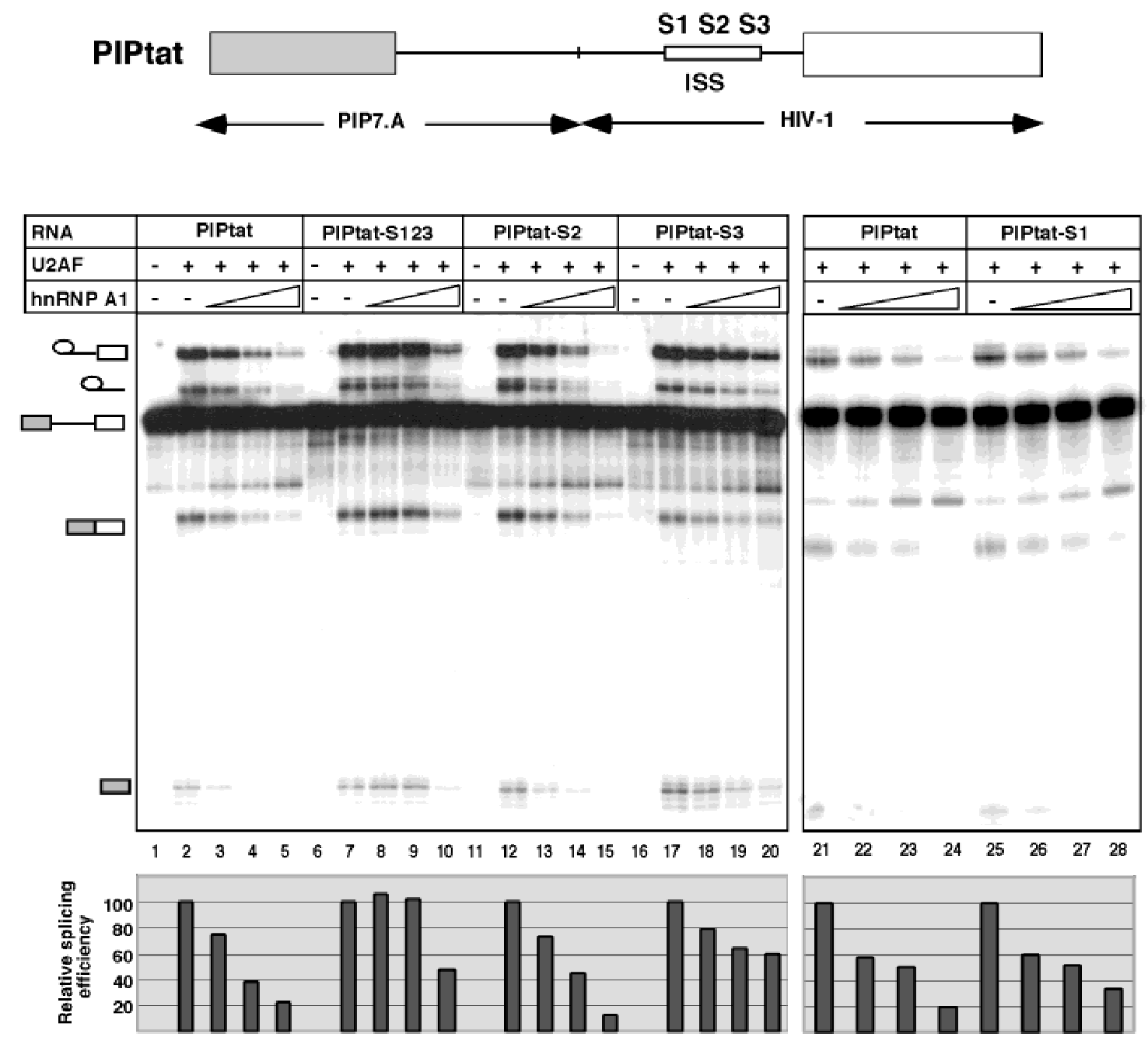

FIGURE 8. In vitro-splicing of wild-type and mutated PiPtat. The parental construct, which is indicated above, contain a non-HIV 5' splice site from PIP7.A fused to the Tat3'ss RNA to ensure that all splicing effects derive from regulatory elements in the Tat3'ss fragment (splicing of PIP7.A is insensitive to hnRNP A1; Tange et al., 2001). The RNA is spliced in U2AF/hnRNP A1-depleted extract (lanes 1, 6, 11, 16), U2AF/hnRNP A1-depleted extract reconstituted with U2AF and no hnRNP A1 (lanes 2, 7, 12, 17, 21, 25), 100 ng of hnRNP A1 (lanes 3, 8, 13, 18, 22, 26), 250 ng of hnRNP A1 (lanes 4, 9, $14,19,23,27)$, or $500 \mathrm{ng}$ of hnRNP A1 (lanes $5,10,15,20,24,28)$. The identities of the splicing products are indicated to the left. 
studied the binding of hnRNP A1 in the context of the native RNA structure.

\section{Determination of a conserved secondary structure in the $3^{\prime}$ splice site region}

Our computer predictions and probing results are consistent with the existence of three major stem loop structures, SL1, SL2, and SL3, of which SL1 and SL3 are conserved in M-type HIV-1. The ISS and the ESS3 are positioned within SL1 and SL3, respectively, whereas the SL2 harbors a GAA repeat at positions 8420-8430, which is part of the degenerate SF2/ASF-dependent enhancer element ESE3 (Mayeda et al., 1999; Tange \& Kjems, 2001). This GAA repeat is highly accessible to chemical modifications by DMS/DEP and single-strand specific RNase cleavage (Fig. 2A, B), consistent with these sequences acting as binding sites for cellular splicing proteins including hnRNP A1 and presumably also SF2/ASF. In contrast, we found that S3, which is the functionally most hnRNP A1 responsive site of the ISS, was less accessible to enzymatic probing reagents and situated in a helix structure adjacent to an internal bulge. Intriguingly, this structure is very similar to the recently reported secondary structural context of the ESS2 (Jacquenet et al., 2001b). The functional significance of this structure is supported by the observation that this base-pairing scheme can form in all investigated M-group viruses (Fig. 3). Another similarity between the ISS and the ESS2 is the appearance of a base-paired UAG element immediately upstream, which corresponds to the S2 sequence of the ISS (Jacquenet et al., 2001b; this report).

\section{Modulation of hnRNP A1 binding by RNA structure}

hnRNP A1 has originally been reported to have a general nonspecific RNA-binding activity, although several reports have specified RNA sequences that are bound by hnRNP A1 with 10-1,000-fold increased affinity (Swanson \& Dreyfuss, 1988; Buvoli et al., 1990; Matunis et al., 1993; Burd \& Dreyfuss, 1994; Mayeda et al.,
1994, 1998; Abdul-Manan et al., 1996; Abdul-Manan \& Williams, 1996; Chabot et al., 1997; Blanchette \& Chabot, 1999; Caputi et al., 1999; Del Gatto-Konczak et al., 1999; Tange et al., 2001; Zhu et al., 2001). A high-affinity binding substrate containing the UAGGGA/U sequence has been defined by SELEX (Burd \& Dreyfuss, 1994), which is consistent with the observation that all known natural targets, including those characterized in this report, contain a conserved UAG motif (see Table 1).

The reported binding affinity $\left(K_{d}\right)$ of hnRNP A1 for various nucleic acid substrates is highly variable, ranging from $1 \mathrm{nM}$ for the strongest binding SELEX RNA substrate UAUGAUAGGGACUUAGGGUG (Burd \& Dreyfuss, 1994) to $1 \mu \mathrm{M}$ for nonspecific RNA (Mayeda et al., 1994, 1998; Abdul-Manan \& Williams, 1996; Shan et al., 2000). Based on the presented gel shift analysis and filter binding assays (C.K. Damgaard \& J. Kjems, unpubl. observations) we have estimated an apparent dissociation constant for hnRNP A1 binding to the HIV-1 ISS and the ESS3 to be approximately 100 nM. A possible explanation for the apparent lower affinity of hnRNP A1 to larger naturally derived substrate RNAs may be that binding occurs in competition with RNA structure. The inhibitory effect that secondary structure may pose on hnRNP A1 binding could explain the observation that the functionality of the ESS3 element is highly dependent on the context in which it is inserted (Staffa \& Cochrane, 1995). In accordance with this, we found that a close match to the extended consensus sequence is not always sufficient for hnRNP A1 binding. Although the S1, S2, and S3 sequences and the ESS3 all contain the UAG motif and exhibit 5 out of $6-n t$ matches to the in vitro-selected sequence, we find that binding of S3 in the RNA most likely is inhibited by RNA structure and dependent on other elements in the RNA. The preference for hnRNP A1 binding to single-stranded regions is consistent with the crystal structure of the complex between the UP1 domain of hnRNP A1 and a TTAGGGTTAGGG (TR2) oligonucleotide (Ding et al., 1999). Here the dTAGG core sequence is recognized in a single-stranded configuration by the beta-sheet platform of the RRMs. Thus, it seems plausible that the

TABLE 1. Splicing silencer elements that bind hnRNP A1. ${ }^{a}$

\begin{tabular}{|c|c|c|}
\hline Origin & Sequence & Reference \\
\hline FGF receptor 2 , K-SAM & UAGGGCAGGC & Del Gatto-Konczak et al. (1999) \\
\hline hnRNP A1 pre-mRNA (CE1) & $\overline{\text { UACCUUUAGAGUAGG }}$ & Chabot et al. (1997) \\
\hline hnRNP A1 pre-mRNA (CE4) & 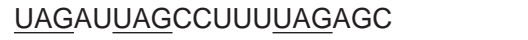 & Blanchette and Chabot (1999) \\
\hline HIV-1 (ESS2 element) & $\overline{\text { CUAGACUAGA }}$ & Amendt et al. (1994, 1995); Caputi et al. (1999) \\
\hline HIV-1 (ESS3 element) & AGAUCCAUUCGAUUAGUGAA & Amendt et al. (1995); Staffa and Cochrane (1995); this report \\
\hline HIV-1 (ESSv element) & UAGGACGUAUAGUUAGUCCUAGGUG & Bilodeau et al. (2001) \\
\hline HIV-1 (ISS element) & UAGUGAAUAGAGUUAGGCA & Tange et al., 2001; this report \\
\hline HIV-1 (GAA loop element) & UAGAAGAAGAAGG & This report \\
\hline
\end{tabular}

${ }^{\text {a }}$ The UAG sequence motifs that represent the core recognition motif for hnRNP A1 (Burd \& Dreyfuss, 1994; Ding et al., 1999) are underlined. 
S3 sequence also is bound in a single-stranded configuration and that a structural rearrangement in the S3 region is required prior to binding. In support of such a model, hnRNP A1 has been reported to exhibit unwinding/annealing activity (Kumar \& Wilson, 1990; Pontius \& Berg, 1990; Munroe \& Dong, 1992; Mayeda et al., 1994; Portman \& Dreyfuss, 1994) and it is possible that hnRNP A1 proteins associated with the putative single-stranded UAG motifs in the ESS3 and/or S1 are responsible for unwinding or rearranging the RNA structure prior to specific recognition of S3. The requirement for the ESS3 element for S3 binding in the Tat3'ss RNA and the increased binding of hnRNP A1 to the Tat-SL1 RNA upon destabilization of the helix is clearly consistent with this model. The cooperativity between the hnRNP A1 binding sites may also involve multimerization of the protein (see discussion below).

\section{hnRNP A1 multimerization}

Our RNA footprinting analysis suggests that the UAGUGA sequence in the ESS3 constitutes a primary recognition site for hnRNPA1 and that binding of hnRNP A1 to this site leads to cooperative binding of additional hnRNP A1 molecules to the GAA repeat loop and the ISS. Similarly, we also found that the ISS also stabilizes binding of hnRNP A1 to the ESS3 to some extent. Interestingly, the ISS and ESS3 are positioned relatively close to each other in the secondary structure model, where the SL1 and SL3 can form a coaxial stacked helix (Fig. 2C). It is possible that this structure promotes cooperative binding of hnRNP A1 to the ESS3 and the ISS. A model for cooperative binding was recently suggested by Zhu et al. (2001), which involves binding of hnRNP A1 to the ESS3 followed by a linear oligomerization along the upstream sequence. This may lead to nucleation of the ESE3 and possibly also regions around SA7 resulting in a decrease in splicing. Our results do support such a cooperative model, although the linear oligomerization of hnRNP A1 is not strictly compatible with our footprinting result, as we observe discrete ribonuclease protection sites at an hnRNP A1 concentration that is sufficient to inhibit splicing completely. Our observations are more consistent with the mechanism that has been suggested for the regulation of the alternative exon $7 \mathrm{~B}$ in the hnRNP A1 mRNA, where hnRNP A1 binds to high-affinity sites flanking the exon and dimerizes, and that this bridging may promote exon skipping (Blanchette \& Chabot, 1999). The ISS, GAA-loop, and ESS3 elements might function in a similar manner, precluding the recognition of essential splicing signals.

In a previous study, we found that the ISS, part of the ESE (corresponding to the GAA repeat), and ESS3 elements inhibited splicing synergistically and in an hnRNP A1-dependent fashion (Tange \& Kjems, 2001; Tange et al., 2001). In the latter study, the ISS was absolutely required for the inhibition of splicing, and its function was further potentiated by the presence of the ESS3. Our present data provide a mechanistic explanation for this observation. Binding of hnRNP A1 to the ISS element blocks U2 snRNP and abrogates splicing, and this process is aided by hnRNP A1 binding to sites in the exon.

In this report, we identified the S3 sequence as the major determinant for ISS function. This conclusion is consistent with an early in vivo study by Staffa and Cochrane (1994) where a UAGG-to-GACG mutation in S3 was made to generate an optimized branchpoint. Accordingly, a marked increase in splicing in COS-7 cells was observed (Staffa \& Cochrane, 1994). At that time, this effect was attributed solely as an effect of increased branching, but our results indicate that this mutation would significantly lower hnRNP A1 binding and thereby contribute to the observed increase in splicing efficiency.

We have recently shown that hnRNP A1 inhibits the formation of the spliceosomal A complex at a step subsequent to U2AF65 binding to the polypyrimidine tract, and we speculated that hnRNP A1 binding sterically blocks the association of SF1/mBBP and/or U2 snRNP (Tange et al., 2001). The primary role of the S3 for splicing inhibition provides further support for this model, as the S3 element coincides precisely with one of the major branchpoints at position -26 (T.Ø. Tange \& J. Kjems, submitted). Concurrently, binding of hnRNP A1 to the S3 region probably also inhibits binding of $\mathrm{U} 2$ snRNP to the branchpoint at position -16 based on the finding that U2 snRNP association involves nonspecific binding of an anchoring region 6-15 nt upstream of the branchpoint (Newnham \& Query, 2001). Binding of hnRNP A1 to other important splicing signals may also contribute to its inhibitory effect. For instance, hnRNP A1 may interfere with binding of positive splicing factors to the GAA repeats in the ESE3 as suggested by Zhu et al. (2001), whereas the unchanged accessibility of regions near the $3^{\prime}$ splice site upon hnRNP A1 binding implies that the recognition of the splice site itself by the spliceosome may not be influenced by hnRNP A1.

One limitation of our study is that only a subfragment of the HIV-1 transcript has been investigated, and it remains to be investigated whether hnRNP A1 molecules associated with other sites in the HIV-1 premRNA may contribute to the binding pattern of hnRNP A1 in the SA7 splice site region.

\section{MATERIALS AND METHODS}

\section{Construction of plasmids}

The GST-hnRNP A1 plasmid has been described previously (Blanchette \& Chabot, 1999). All constructs were made using standard PCR and cloning techniques (Sambrook et al., 1989). 
The pBS-tat, which covers the HIV-1 isolate HXB3 (GenBank M14100) nt 5811-6158 and 8141-8486 (GenBank K03455; HXB2 numbering) has also been described elsewhere (Tange et al., 2001). This construct was used as parental plasmid for constructing wild-type and point-mutation/deletion mutants in pBS-Tat3'ss covering the last $65 \mathrm{nt}$ of the tat/rev intron and the first 108 nt of the third tat exon (8314-8486; HXB2 numbering). pBS-Tat3'ss, pBS-Tat3'ss-S123, pBS-Tat3'ss-S1, pBS-Tat3'ss-S2, pBS-Tat3'ss-S3, and pBS-Tat3'ss-cS2 were generated by standard PCR techniques and site-directed mutagenesis, producing PCR fragments with tags containing EcoRI and HindIII sites that were inserted between the EcoRI and HindIII sites of pBS $(+)$. See Figure 1 for sequences of mutagenized regions. These plasmids were linearized at either Aval or HindlII to generate RNAs spanning regions 83148394 or 8314-8486 (HXB2). pBS-PIPtat-S123, pBS-PIPtatS1, pBS-PIPtat-S2, and pBS-PIPtat-S3 were constructed by standard site-directed mutagenesis, producing PCR fragments with tags containing Sall and HindIII sites that were inserted into either Sall or HindIII digested pBS-PIPtat (Tange et al., 2001). All constructs were verified by sequencing.

\section{Protein expression}

GST-hnRNP A1 was expressed and purified essentially as described in Blanchette and Chabot (1999) and kept in GST-hnRNP A1 buffer (20 mM HEPES/KOH, pH 7.9, 150 mM $\mathrm{KCl}, 20 \%$ glycerol, $1 \mathrm{mM}$ DTT, $0.2 \mathrm{mM}$ EDTA). Protein concentrations were measured by the method of Bradford (BioRad) and/or estimated from Coomassie Blue stained SDSpolyacrylamide gels using serial dilutions of bovine serum albumin as standard.

\section{In vitro transcription}

Internally labeled Tat3'ss-derived RNAs were prepared by standard in vitro run-off transcription with [ $\left.\alpha{ }^{-32} \mathrm{P}\right]$ UTP (20 $\mathrm{mCi} / \mathrm{mL}, 800 \mathrm{Ci} / \mathrm{mmol}$; Pharmacia) using T7 RNA polymerase (USB). Final nucleotide concentrations in reactions were: GpppG, $1 \mathrm{mM}$; ATP, $0.4 \mathrm{mM}$; CTP, $0.4 \mathrm{mM}$; GTP, $0.1 \mathrm{mM}$; UTP, $0.04 \mathrm{mM}$; and [ $\left.\alpha^{-}{ }^{32} \mathrm{P}\right]-U T P, 0.002 \mathrm{mM}$. All transcripts were gel purified and concentrations determined by scintillation counting. pBS-Tat3'ss or pBS-PIPtat-derived templates were generated by linearization with Aval to produce SL1 constructs or Hindlll for full-length exon constructs. Preparative amounts of nonlabeled Tat3'ss RNA was generated using Megascript T7 transcription kit (Ambion) according to the manufacturer's protocol and RNA was subsequently gel purified. $5^{\prime}$ and $3^{\prime}$ end labeling was done as described in Damgaard et al. (1998).

\section{Electrophoretic mobility shift assays}

RNA-hnRNP A1 complexes were prepared by mixing $1 \mu \mathrm{L}$ (0-300 ng) GST-hnRNP A1 in GST-hnRNP A1 buffer, $5 \mu \mathrm{L}$ $2 \times$ binding buffer (20 mM HEPES/KOH, pH 7.6, $200 \mathrm{mM}$ $\mathrm{KCl}, 4 \mathrm{mM} \mathrm{MgCl}$, $1 \mathrm{mM}$ EDTA, 2 mM DTT, 20\% glycerol, 240 $\mathrm{ng} / \mu \mathrm{L}$ rRNA); $0.1 \mu \mathrm{L}$ RNasin $(40 \mathrm{U} / \mu \mathrm{L}), 2.9 \mu \mathrm{L} \mathrm{H} \mathrm{H}_{2} \mathrm{O}$, and $1 \mu \mathrm{L}$ labeled RNA ( $5 \mathrm{fmol}$ ) that was renatured by heating to $75^{\circ} \mathrm{C}$ for $5 \mathrm{~min}$ and subsequently cooled slowly to room temperature in renaturation buffer (20 mM HEPES/KOH, pH 7.6,
$100 \mathrm{mM} \mathrm{KCl}$ ) and kept on ice. The reactions were mixed and incubated for $15 \mathrm{~min}$ at room temperature and run on a native $6 \%$ polyacrylamide gel containing $100 \mathrm{mM}$ Tris/borate, $\mathrm{pH} 8.3$, and $1 \mathrm{mM}$ EDTA $(1 \times$ TBE).

\section{Enzymatic and chemical RNA probing}

Probing was essentially done as described previously (Damgaard et al., 1998). Five hundred nanograms of either $5^{\prime}$ or $3^{\prime}$ end-labeled RNA was renatured as described above. A mixture of $48 \mu \mathrm{L} 5 \times$ probing buffer (50 mM HEPES/KOH, $\mathrm{pH} 7.6$; $500 \mathrm{mM} \mathrm{KCl}, 10 \mathrm{mM} \mathrm{MgCl}_{2}$, $2.5 \mathrm{mM}$ EDTA, $5 \mathrm{mM}$ DTT, 50\% glycerol (v/v)), $50 \mu \mathrm{g} r R N A$, and $\mathrm{dd}_{2} \mathrm{O}$ to a final volume of $230 \mu \mathrm{L}$ was added to $10 \mu \mathrm{L}$ of renatured RNA. This mixture was split into twelve $20-\mu \mathrm{L}$ aliquots, each of which was incu-

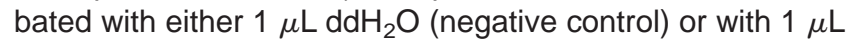
of RNase $T_{1}(1-10 \mathrm{U} / \mathrm{mL})$ or $1 \mu \mathrm{L}$ RNase $T_{2}(2-10 \mathrm{U} / \mathrm{mL})$ or $1 \mu \mathrm{L}$ RNase $\mathrm{V}_{1}(10-50 \mathrm{U} / \mathrm{mL})$. After incubation for $13 \mathrm{~min}$ on ice, reactions were terminated with $180 \mu \mathrm{L} 300 \mathrm{mM} \mathrm{NaAc}$, pH 6.0 and 2 mM EDTA and reactions were phenol extracted twice and the RNA was precipitated. The RNA pellets were redissolved in $10 \mu \mathrm{L} \mathrm{95 \%} \mathrm{formamide} \mathrm{loading} \mathrm{buffer.} \mathrm{Samples}$ were heated to $95^{\circ} \mathrm{C}$ for $3 \mathrm{~min}$ and resolved on a $6-8 \%$ denaturing polyacrylamide gel containing $8 \mathrm{M}$ urea, $100 \mathrm{mM}$ Tris/borate, $\mathrm{pH}$ 8.3, and $1 \mathrm{mM}$ EDTA. Alkaline hydrolysis ladder was prepared by incubating end-labeled RNA $(50,000$ $\mathrm{cpm}$ ) in $2 \times$ alkaline hydrolysis buffer (100 $\mathrm{mM} \mathrm{NaHCO}_{3} /$ $\mathrm{Na}_{2} \mathrm{CO}_{3}, \mathrm{pH}$ 9.0, $2 \mathrm{mM}$ EDTA, $0.5 \mu \mathrm{g} / \mu \mathrm{L}$ tRNA) at $96^{\circ} \mathrm{C}$ for 5-10 min. $G$ and $A$ sequences were generated by incubating end-labeled lyophilized RNA (50,000 cpm) with $1 \mu \mathrm{L} 0.05$ $\mathrm{U} / \mu \mathrm{L}$ RNase T1 (G specific) or $1 \mu \mathrm{L} 0.005 \mathrm{U} / \mu \mathrm{L}$ RNase U2 (A specific) in either $10 \mu \mathrm{L} \mathrm{G}$ buffer (20 mM NaCitrate, $\mathrm{pH} 5.0$, $1 \mathrm{mM}$ EDTA, $7 \mathrm{M}$ urea, $0.025 \%$ xylene cyanol, $0.025 \%$ bromphenol blue) or $10 \mu \mathrm{L}$ A buffer (20 mM NaCitrate, $\mathrm{pH} 3.5$, $1 \mathrm{mM}$ EDTA, $7 \mathrm{M}$ urea, $0.025 \%$ xylene cyanol, $0.025 \%$ bromphenol blue), respectively, at $50^{\circ} \mathrm{C}$ for $15 \mathrm{~min}$. Chemical probing was done by incubating $200 \mu \mathrm{L}$ modification buffer $(70 \mathrm{mM}$ HEPES KOH, pH 7.8, $\left.10 \mathrm{mM} \mathrm{MgCl}_{2}, 270 \mathrm{mM} \mathrm{KCl}\right), 10$ pmol renatured RNA, and either $1 \mu \mathrm{L}$ DMS (freshly diluted 1:2 in $96 \% \mathrm{EtOH}(\mathrm{v} / \mathrm{v}))$ or $5 \mu \mathrm{L} \mathrm{DEP}$ at $0^{\circ} \mathrm{C}$ for $30-60 \mathrm{~min}$. DMS reaction was terminated by adding $50 \mu \mathrm{L}$ DMS termination buffer (1 M Tris acetate, $\mathrm{pH} 7.5,1 \mathrm{M} \beta$-mercaptoethanol, $1.5 \mathrm{M} \mathrm{NaAc}, 0.1 \mathrm{mM}$ EDTA) and RNA was precipitated. DEP reaction was terminated by adding $20 \mu \mathrm{L} 3 \mathrm{M} \mathrm{NaAc}, \mathrm{pH} 6.0$, and RNA precipitated with $\mathrm{EtOH}$. Both pellets are redissolved in $0.3 \mathrm{M} \mathrm{NaAc}, \mathrm{pH}$ 6.0, phenol extracted, and precipitated again. The RNA was redissolved in $10 \mu \mathrm{L}$ and subjected to primer extension using a $5^{\prime}$ end-labeled primer. Each of the $2.4 \mu \mathrm{L}$ RNA reactions were annealed to $0.2 \mathrm{pmol}(3 \mu \mathrm{L})$ of a 5 ' end-labeled primer by adding $0.6 \mu \mathrm{L} 10 \times$ anneal buffer (100 mM Tris- $\mathrm{HCl}, \mathrm{pH} 6.9,400 \mathrm{mM} \mathrm{KCl,} 5 \mathrm{mM}$ EDTA) and incubating at $95^{\circ} \mathrm{C}$ for $1 \mathrm{~min}$, then transferred to a $50^{\circ} \mathrm{C}$ water bath for another $10 \mathrm{~min}$, after which the reactions were put on ice. To each reaction, $1 \mu \mathrm{L}$ of a $10 \times \mathrm{RT}$ buffer $(500 \mathrm{mM}$ Tris- $\mathrm{HCl}, \mathrm{pH} 8.4,100 \mathrm{mM} \mathrm{MgCl} 2,20 \mathrm{mM}$ DTT) was added plus $2.9 \mu \mathrm{L}$ dNTP mix (2.5 mM of each nucleotide) and $0.1 \mu \mathrm{L}$ of AMV reverse transcriptase (Pharmacia Biotech, $2 \mathrm{U} /$ reaction), and incubated at $46^{\circ} \mathrm{C}$ for $30 \mathrm{~min}$. The reactions were terminated by addition of $40 \mu \mathrm{L}$ of $300 \mathrm{mM} \mathrm{NaAc}, \mathrm{pH} 6.0$, and samples were precipitated. A DNA marker sequence was obtained by adding dideoxy nucleotides to reverse transcription reactions using untreated $\mathrm{RNA}$ as a template. The cDNA 
samples were resolved in a $6-8 \%$ denaturing polyacrylamide gel containing $8 \mathrm{M}$ urea, $100 \mathrm{mM}$ Tris/borate, $\mathrm{pH} 8.3$, and $1 \mathrm{mM}$ EDTA.

\section{RNA footprinting}

Five hundred nanograms of either $5^{\prime}$ or $3^{\prime}$ end-labeled RNA were renatured as described above. A mixture of $48 \mu \mathrm{L} 5 \times$ probing buffer, $50 \mu \mathrm{g} r \mathrm{RNA}$, and $\mathrm{ddH}_{2} \mathrm{O}$ to a final volume of $210 \mu \mathrm{L}$ was added to the renatured RNA. This mixture was split into three $70-\mu \mathrm{L}$ aliquots, each of which was incubated with $10 \mu \mathrm{L}$ of either hnRNP A1 storage buffer or 0.75 to $1.5 \mu \mathrm{g}$ of hnRNP A1. After incubation for $15 \mathrm{~min}$ at room temperature, each reaction was further split into four $15-\mu \mathrm{L}$ aliquots to which either $1 \mu \mathrm{L} \mathrm{ddH}_{2} \mathrm{O}$ (negative control) or $1 \mu \mathrm{L}$ RNase $\mathrm{T}_{1}(1 \mathrm{U} / \mathrm{mL})$ or $1 \mu \mathrm{L}$ RNase $\mathrm{T}_{2}(2 \mathrm{U} / \mathrm{mL})$ or $1 \mu \mathrm{L}$ RNase $V_{1}(30 \mathrm{U} / \mathrm{mL})$ was added on ice. After incubation for $13 \mathrm{~min}$ on ice, reactions were terminated with $185 \mu \mathrm{L} 300 \mathrm{mM}$ $\mathrm{NaAc}, \mathrm{pH} 6.0$, and reactions were phenol extracted twice and the RNA was precipitated. The RNA pellets were redissolved in $10 \mu \mathrm{L} 95 \%$ formamide loading buffer. Samples were heated to $95^{\circ} \mathrm{C}$ for $3 \mathrm{~min}$ and resolved in a $6-8 \%$ denaturing polyacrylamide gel containing $8 \mathrm{M}$ urea, $100 \mathrm{mM}$ Tris/borate, $\mathrm{pH}$ 8.3, and $1 \mathrm{mM}$ EDTA.

\section{In vitro splicing assays}

Splicing reactions with oligo(dT) $\Delta \mathrm{NE}$ (HeLa nuclear extract; $\sim 10 \mu \mathrm{g} / \mu \mathrm{L}$; 4C, Belgium; Tange et al., 2001) were prepared by mixing $3 \mu \mathrm{L}$ oligo-(dT) $\Delta \mathrm{NE}, 1 \mu \mathrm{L}$ buffer $\mathrm{D}(100 \mathrm{mM} \mathrm{KCl}$, 20\% glycerol, $20 \mathrm{mM}$ HEPES KOH, pH 7.9, 0.2 mM EDTA, $1 \mathrm{mM}$ DTT), $1 \mu \mathrm{L}$ U2AF or $1 \mu \mathrm{L}$ buffer D, $1 \mu \mathrm{L} 10 \times$ splice buffer (25 mM MgCl $2,5 \mathrm{mM}$ ATP, $200 \mathrm{mM}$ creatine phosphate, $3.5 \mathrm{mM}$ DTT, $3.2 \mathrm{U} / \mu \mathrm{L}$ RNasin (Promega)), $2 \mu \mathrm{L} 15 \%$ polyvinyl alcohol (PVA), $1 \mu \mathrm{L}$ GST-hnRNP A1 (100-500 ng) or storage buffer (20 mM HEPES/KOH, pH 7.9, $150 \mathrm{mM} \mathrm{KCl}$, 20\% glycerol, $1 \mathrm{mM}$ DTT, $0.2 \mathrm{mM}$ EDTA), and $1 \mu \mathrm{L}$ labeled PIPtat-derived pre-mRNA (5-10 fmol). The reactions were incubated at $30^{\circ} \mathrm{C}$ for $2 \mathrm{~h}$ and stopped by addition of $190 \mu \mathrm{L}$ splice stop buffer (300 mM NaCH${ }_{3} \mathrm{COO}, \mathrm{pH} 6.0,0.5 \%$ SDS, $100 \mathrm{mM} \mathrm{NaCl}, 20 \mathrm{mM}$ Tris/HCl, $\mathrm{pH}$ 7.5, $5 \mathrm{mM}$ EDTA, $0.03 \mu \mathrm{g} / \mu \mathrm{L}$ bulk Escherichia coli tRNA). After $1 \times$ phenol extraction, $1 \times$ chloroform extraction, and ethanol precipitation, the samples were resuspended in RNA loading buffer $(90 \%$ formamide, $1 \mathrm{mM}$ EDTA, 0.05\% bromophenol blue, and $0.05 \%$ xylene cyanol), heated at $95^{\circ} \mathrm{C}$ for $3 \mathrm{~min}$, and applied to a denaturing $6 \%$ polyacrylamide gel containing $0.75 \times \mathrm{TBE}$.

\section{ACKNOWLEDGMENTS}

We are grateful to Jim Manley for SF2/ASF plasmid, Benoit Chabot for hnRNP A1 plasmid, and Rita Rosendahl for excellent technical assistance. The work was supported in parts by grants from the Danish Medical and Natural Research Councils, the Karen Elise Jensen Foundation, the Danish AIDS Foundation, and the Carlsberg Foundation. C.K.D. and T.Ø.T were supported by University of Aarhus.

Received January 22, 2002; returned for revision February 14, 2002; revised manuscript received August 30, 2002

\section{REFERENCES}

Abdul-Manan N, O'Malley SM, Williams KR. 1996. Origins of binding specificity of the $A 1$ heterogeneous nuclear ribonucleoprotein. Biochemistry 35:3545-3554.

Abdul-Manan N, Williams KR. 1996. hnRNP A1 binds promiscuously to oligoribonucleotides: Utilization of random and homooligonucleotides to discriminate sequence from base-specific binding. Nucleic Acids Res 24:4063-4070.

Amendt BA, Hesslein D, Chang LJ, Stoltzfus CM. 1994. Presence of negative and positive cis-acting RNA splicing elements within and flanking the first tat coding exon of human immunodeficiency virus type 1. Mol Cell Biol 14:3960-3970.

Amendt BA, Si ZH, Stoltzfus CM. 1995. Presence of exon splicing silencers within human immunodeficiency virus type 1 tat exon 2 and tat-rev exon 3: Evidence for inhibition mediated by cellular factors. Mol Cell Biol 15:4606-4615.

Bilodeau PS, Domsic JK, Mayeda A, Krainer AR, Stoltzfus CM. 2001 RNA splicing at human immunodeficiency virus type $13^{\prime}$ splice site $A 2$ is regulated by binding of hnRNP A/B proteins to an exonic splicing silencer element. J Virol 75:8487-8497.

Blanchette M, Chabot B. 1999. Modulation of exon skipping by highaffinity hnRNP A1-binding sites and by intron elements that repress splice site utilization. EMBO J 18:1939-1952.

Burd CG, Dreyfuss G. 1994. RNA binding specificity of hnRNP A1: Significance of hnRNP A1 high-affinity binding sites in pre-mRNA splicing. EMBO J 13:1197-1204.

Buvoli M, Cobianchi F, Biamonti G, Riva S. 1990. Recombinant hnRNP protein $\mathrm{A} 1$ and its $\mathrm{N}$-terminal domain show preferential affinity for oligodeoxynucleotides homologous to intron/exon acceptor sites. Nucleic Acids Res 18:6595-6600.

Caputi M, Mayeda A, Krainer AR, Zahler AM. 1999. hnRNP A/B proteins are required for inhibition of HIV-1 pre-mRNA splicing. EMBO J 18:4060-4067.

Carson JH, Kwon S, Barbarese E. 1998. RNA trafficking in myelinating cells. Curr Opin Neurobiol 8:607-612.

Chabot B, Blanchette M, Lapierre I, La Branche H. 1997. An intron element modulating $5^{\prime}$ splice site selection in the hnRNP A1 premRNA interacts with hnRNP A1. Mol Cell Biol 17:1776-1786.

Cobianchi F, Karpel RL, Williams KR, Notario V, Wilson SH. 1988. Mammalian heterogeneous nuclear ribonucleoprotein complex protein A1. Large-scale overproduction in Escherichia coli and cooperative binding to single-stranded nucleic acids. $\mathrm{J}$ Biol Chem 263:1063-1071.

Dallaire F, Dupuis S, Fiset S, Chabot B. 2000. Heterogeneous nuclear ribonucleoprotein $\mathrm{A} 1$ and UP1 protect mammalian telomeric repeats and modulate telomere replication in vitro. $\mathrm{J} \mathrm{Biol} \mathrm{Chem}$ 275:14509-14516.

Damgaard CK, Dyhr-Mikkelsen H, Kjems J. 1998. Mapping the RNA binding sites for human immunodeficiency virus type-1 gag and $\mathrm{NC}$ proteins within the complete HIV-1 and -2 untranslated leader regions. Nucleic Acids Res 26:3667-3676.

Del Gatto-Konczak F, Olive M, Gesnel MC, Breathnach R. 1999. hnRNP A1 recruited to an exon in vivo can function as an exon splicing silencer. Mol Cell Biol 19:251-260.

Ding J, Hayashi MK, Zhang Y, Manche L, Krainer AR, Xu RM. 1999. Crystal structure of the two-RRM domain of hnRNP A1 (UP1) complexed with single-stranded telomeric DNA. Genes \& Dev 13:1102-1115.

Dyhr-Mikkelsen H, Kjems J. 1995. Inefficient spliceosome assembly and abnormal branch site selection in splicing of an HIV-1 transcript in vitro. J Biol Chem 270:24060-24066.

Eperon IC, Ireland DC, Smith RA, Mayeda A, Krainer AR. 1993. Pathways for selection of $5^{\prime}$ splice sites by U1 snRNPs and SF2/ ASF. EMBO J 12:3607-3617.

Eperon IC, Makarova OV, Mayeda A, Munroe SH, Caceres JF, Hayward DG, Krainer AR. 2000. Selection of alternative 5' splice sites: Role of U1 snRNP and models for the antagonistic effects of SF2/ASF and hnRNP A1. Mol Cell Biol 20:8303-8318.

Fiset S, Chabot B. 2001. hnRNP A1 may interact simultaneously with telomeric DNA and the human telomerase RNA in vitro. Nucleic Acids Res 29:2268-2275.

Hoek KS, Kidd GJ, Carson JH, Smith R. 1998. hnRNP A2 selectively binds the cytoplasmic transport sequence of myelin basic protein mRNA. Biochemistry 37:7021-7029. 
Ishikawa F, Matunis MJ, Dreyfuss G, Cech TR. 1993. Nuclear proteins that bind the pre-mRNA 3' splice site sequence $r(U U A G / G)$ and the human telomeric DNA sequence d(TTAGGG)n. Mol Cell Biol 13:4301-4310.

Izaurralde E, Jarmolowski A, Beisel C, Mattaj IW, Dreyfuss G, Fischer U. 1997. A role for the M9 transport signal of hnRNP A1 in mRNA nuclear export. J Cell Biol 137:27-35.

Jacquenet S, Mereau A, Bilodeau PS, Damier L, Stoltzfus CM, Branlant C. 2001a. A second exon splicing silencer within human immunodeficiency virus type 1 tat exon 2 represses splicing of Tat mRNA and binds protein hnRNP H. J Biol Chem 276:4046440475.

Jacquenet S, Ropers D, Bilodeau PS, Damier L, Mougin A, Stoltzfus CM, Branlant C. 2001b. Conserved stem-loop structures in the HIV-1 RNA region containing the $\mathrm{A} 33^{\prime}$ splice site and its cisregulatory element: Possible involvement in RNA splicing. Nucleic Acids Res 29:464-478.

Kammler S, Leurs C, Freund M, Krummheuer J, Seidel K, Tange TO, Lund MK, Kjems J, Scheid A, Schaal H. 2001. The sequence complementarity between HIV-1 5' splice site SD4 and U1 snRNA determines the steady-state level of an unstable env pre-mRNA. RNA 7:421-434.

Kumar A, Wilson SH. 1990. Studies of the strand-annealing activity of mammalian hnRNP complex protein A1. Biochemistry 29: 10717-10722.

LaBranche H, Dupuis S, Ben-David Y, Bani MR, Wellinger RJ, Chabot B. 1998. Telomere elongation by hnRNP A1 and a derivative that interacts with telomeric repeats and telomerase. Nat Genet 19: 199-202.

Matunis EL, Matunis MJ, Dreyfuss G. 1993. Association of individual hnRNP proteins and snRNPs with nascent transcripts. J Cell Biol 121:219-228.

Mayeda A, Krainer AR. 1992. Regulation of alternative pre-mRNA splicing by hnRNP A1 and splicing factor SF2. Cell 68:365-375.

Mayeda A, Munroe SH, Caceres JF, Krainer AR. 1994. Function of conserved domains of hnRNP A1 and other hnRNP A/B proteins. EMBO J 13:5483-5495.

Mayeda A, Munroe SH, Xu RM, Krainer AR. 1998. Distinct functions of the closely related tandem RNA-recognition motifs of hnRNP A1. RNA 4:1111-1123.

Mayeda A, Screaton GR, Chandler SD, Fu XD, Krainer AR. 1999. Substrate specificities of SR proteins in constitutive splicing are determined by their RNA recognition motifs and composite premRNA exonic elements. Mol Cell Biol 19:1853-1863.

Munro TP, Magee RJ, Kidd GJ, Carson JH, Barbarese E, Smith LM, Smith R. 1999. Mutational analysis of a heterogeneous nuclear ribonucleoprotein $\mathrm{A} 2$ response element for RNA trafficking. J Biol Chem 274:34389-34395.

Munroe SH, Dong XF. 1992. Heterogeneous nuclear ribonucleoprotein A1 catalyzes RNA.RNA annealing. Proc Natl Acad Sci USA 89:895-899.

Newnham CM, Query CC. 2001. The ATP requirement for U2 snRNP addition is linked to the pre-mRNA region $5^{\prime}$ to the branch site. RNA 7:1298-1309.

O'Reilly MM, McNally MT, Beemon KL. 1995. Two strong 5' splice sites and competing, suboptimal $3^{\prime}$ splice sites involved in alter- native splicing of human immunodeficiency virus type 1 RNA. Virology 213:373-385.

Pontius BW, Berg P. 1990. Renaturation of complementary DNA strands mediated by purified mammalian heterogeneous nuclear ribonucleoprotein A1 protein: Implications for a mechanism for rapid molecular assembly. Proc Natl Acad Sci USA 87:8403-8407.

Portman DS, Dreyfuss G. 1994. RNA annealing activities in HeLa nuclei. EMBO J 13:213-221.

Purcell DF, Martin MA. 1993. Alternative splicing of human immunodeficiency virus type 1 mRNA modulates viral protein expression, replication, and infectivity. $J$ Virol 67:6365-6378.

Sambrook J, Fritsch EF, Maniatis T. 1989. Molecular cloning: A laboratory manual, 2nd ed. Cold Spring Harbor, New York: Cold Spring Harbor Laboratory Press.

Shamoo Y, Abdul-Manan N, Williams KR. 1995. Multiple RNA binding domains (RBDs) just don't add up. Nucleic Acids Res 23:725-728.

Shan J, Moran-Jones K, Munro TP, Kidd GJ, Winzor DJ, Hoek KS, Smith R. 2000. Binding of an RNA trafficking response element to heterogeneous nuclear ribonucleoproteins $\mathrm{A} 1$ and A2. J Biol Chem 275:38286-38295.

Si Z, Amendt BA, Stoltzfus CM. 1997. Splicing efficiency of human immunodeficiency virus type 1 tat RNA is determined by both a suboptimal $3^{\prime}$ splice site and a 10 nucleotide exon splicing silencer element located within tat exon 2. Nucleic Acids Res 25:861-867.

Si ZH, Rauch D, Stoltzfus CM. 1998. The exon splicing silencer in human immunodeficiency virus type 1 Tat exon 3 is bipartite and acts early in spliceosome assembly. Mol Cell Biol 18:5404-5413.

Staffa A, Cochrane A. 1994. The tat/rev intron of human immunodeficiency virus type 1 is inefficiently spliced because of suboptimal signals in the 3' splice site. J Virol 68:3071-3079.

Staffa A, Cochrane A. 1995. Identification of positive and negative splicing regulatory elements within the terminal tat-rev exon of human immunodeficiency virus type 1. Mol Cell Biol 15:45974605.

Swanson MS, Dreyfuss G. 1988. RNA binding specificity of hnRNP proteins: A subset bind to the $3^{\prime}$ end of introns. EMBO $J$ 7:35193529.

Tange TO, Damgaard CK, Guth S, Valcarcel J, Kjems J. 2001. The hnRNP A1 protein regulates HIV-1 tat splicing via a novel intron silencer element. EMBO J 20:5748-5758.

Tange TO, Kjems J. 2001. SF2/ASF binds to a splicing enhancer in the third HIV-1 tat exon and stimulates U2AF binding independently of the RS domain. $J$ Mol Biol 312:649-662.

Visa N, Alzhanova-Ericsson AT, Sun X, Kiseleva E, Bjorkroth B, Wurtz T, Daneholt B. 1996. A pre-mRNA-binding protein accompanies the RNA from the gene through the nuclear pores and into polysomes. Cell 84:253-264.

Yang X, Bani MR, Lu SJ, Rowan S, Ben-David Y, Chabot B. 1994. The $\mathrm{A} 1$ and $\mathrm{A} 1 \mathrm{~B}$ proteins of heterogeneous nuclear ribonucleoparticles modulate $5^{\prime}$ splice site selection in vivo. Proc Natl Acad Sci USA 91:6924-6928.

Zhu J, Mayeda A, Krainer AR. 2001. Exon identity established through differential antagonism between exonic splicing silencer-bound hnRNP A1 and enhancer-bound SR proteins. Mol Cell 8:13511361. 

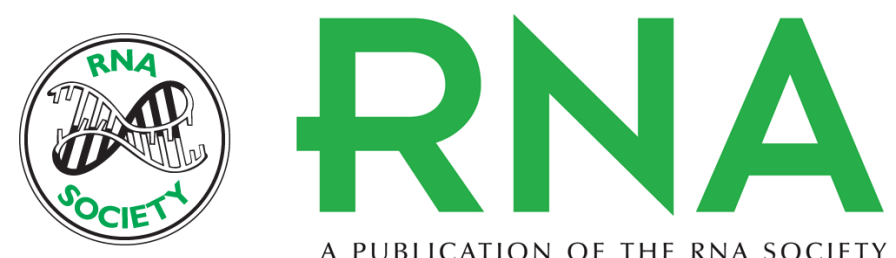

A PUBLICATION OF THE RNA SOCIETY

\section{hnRNP A1 controls HIV-1 mRNA splicing through cooperative binding to intron and exon splicing silencers in the context of a conserved secondary structure.}

Christian Kroun Damgaard, Thomas Ostergaard Tange and Jørgen Kjems

RNA 2002 8: 1401-1415

License

Email Alerting Receive free email alerts when new articles cite this article - sign up in the box at the Service top right corner of the article or click here.

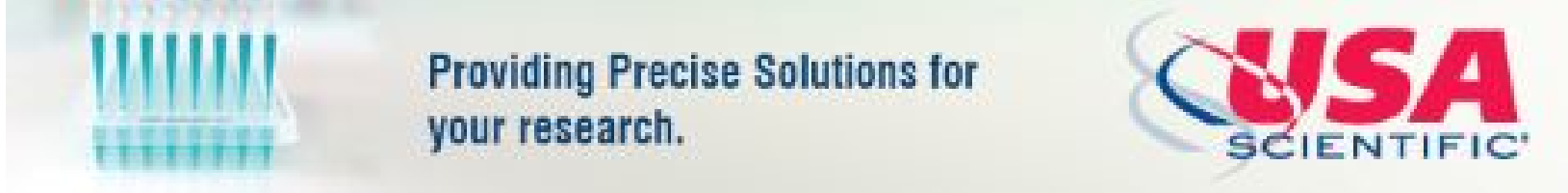

To subscribe to RNA go to:

http://rnajournal.cshlp.org/subscriptions 